\title{
Comparative study of a woman's discoursein the two novels "Siraj" by Radwa Ashour and "Savushun" by Simin Daneshvar in light of the realism
}

Fatemeh Akbarizadeh

f.akbarizadeh@alzahra.ac.ir.

Assistant Professor, Department of Arabic Language and Literature, Alzahra University, Tehran. (Coresponding Author)

Masoumeh Nagravi

negravi321@gmail.com

Graduate of Arabic Language and Literature, Alzahra University, Tehran.

\section{Abstract}

Women in the Egyptian and Iranian society have played a prominent role in contemporary social and political events whereas Creative female personalities, such as the Iranian "Simin Daneshvar" and the Egyptian "Radwi Ashour"appeared in the novel. In fact, they were interested in portraying the role of women in society through the writing of the novels "Siraj" by Radwa Ashour and "Savushun" by Simin Daneshvar. For this reason, the research has dealt with the overlap of the two narratives and on the general discourse prevailing over them in order to stand on the faces of the intended discourse of these two writers, approaching the analytical descriptive method, based on the realist school according to the feminist critical comparison approach in light of the American school of comparative literature. The research found that the two narratives overlap in terms of monitoring the social contents and real events in their society, and for this reason, the prevailing discourse became embodied in the historical discourse, and a return to history to monitor a social discourse to depict the role of women in Iranian and Arab society, while the two narratives abound with intense vocabulary, expressions and descriptions that depict women. In vocabulary and expressions so that an attempt was made to suggest the role of women and broadcast the woman's voice through internal dialogue and retrieval of time from history, and for this the end of the two novels was a pioneering role for women in a feminist discourse and this stage passed through an emotional experience of the writers with social events and political facts in their Iranian and Arab countries for an honest expression 


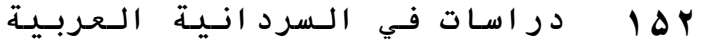

that fulfills the feminist discourse And historical passing through the heritage.

Key words: comparison, Realism, Siraj, Radwa Ashour, Savushun, Simin Daneshvar.

Citation: Akbarizadeh, Fatemeh; Nagravi, Masoumeh; Autumn \& Winter (20202021). Comparative study of a woman's discoursein the two novels "Siraj" by Radwa Ashour and "Savushun" by Simin Daneshvar in light of the realism. Studies in Arabic Narratology, 2(3), 151-172. (In Arabic)

Studies in Arabic Narratology, Autumn \& Winter (2020-2021), Vol. 2, No.3, pp. 151-172

Received: August 2, 2020; Accepted: March 2, 2021

(C) Faculty of Literature \& Humanities, University of Kharazmi and Iranian Association of Arabic Language \& Literature. 


$$
\text { مـوز انــة بـين رو ايـتي "سر اج" و "سووشون" علـي ضوء }
$$

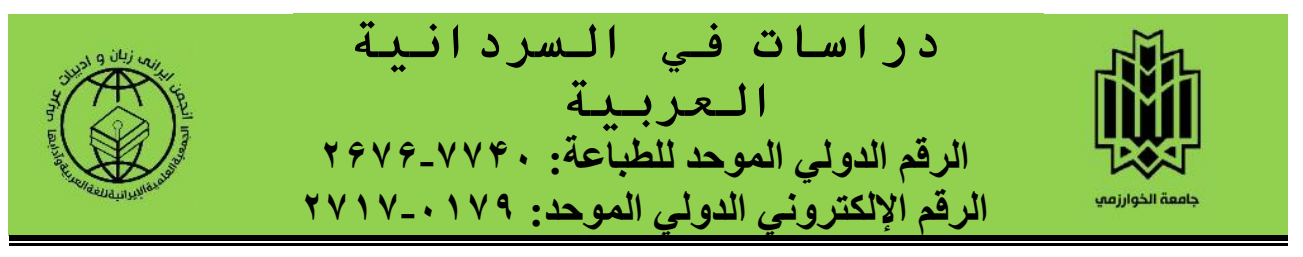

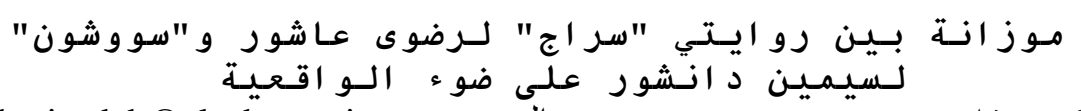
f.akbarizadeh@alzahra.ac.ir البرويد فاطمة أكبري زاده الإلكتروني: - البريد

أستاذة مساعدة في قسم اللغة العربية وآدابها بجامعة الزئزئ هراء، طهر ان (الكاتبة المسؤولة) negravi321@gmail.com البريد

$$
\begin{aligned}
& \text { الإلكتروني: البريد } \\
& \text { خريجة الماجستير في فرع اللغة العربية وآدابها، جامعة الزهر اءو، طهران. }
\end{aligned}
$$

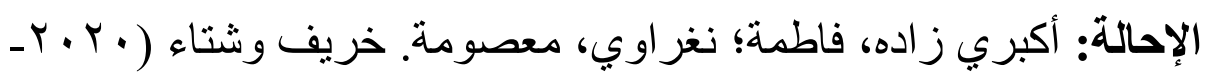

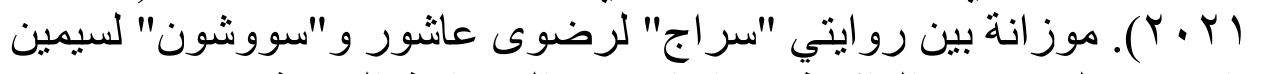

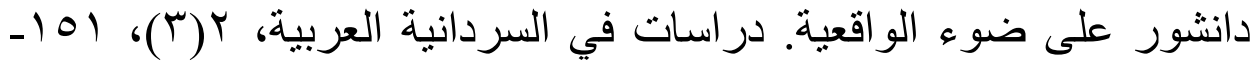

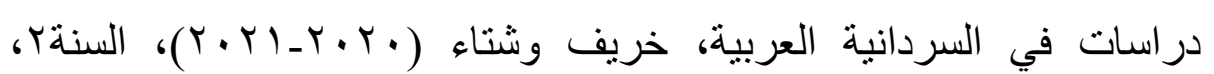

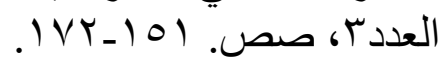

$$
\text { تاريخ الوصول: }
$$

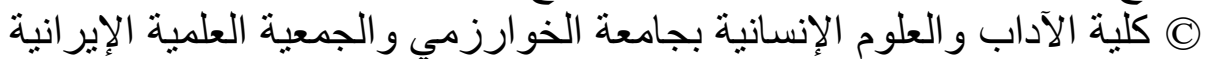
للغة العربية و آدابها.

$$
\text { الـمـلـخص وله }
$$

مثلت المرأة في المجتمع العربي والإيراني دورا بارزا في الإني

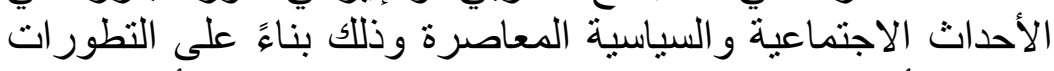

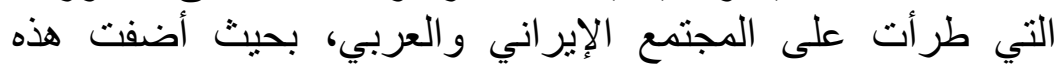

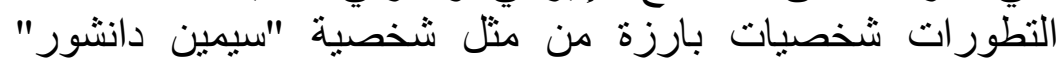

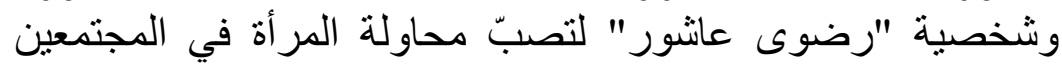

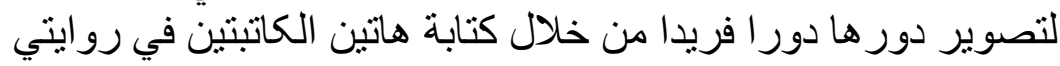

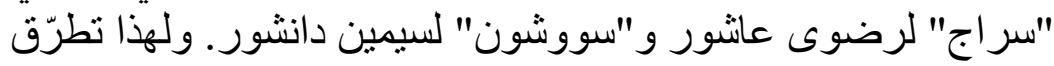
البحث إلى معالجة تداخل الروايتين وإلى تلى تناول الخطاب العام السائد 
على الروايتين ليقف على وجوه التداخل لدى الكاتبات في العالم

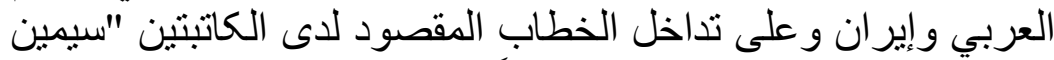

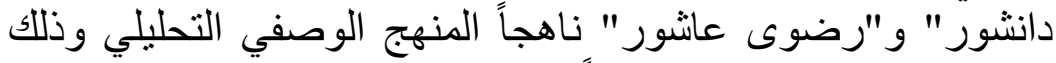

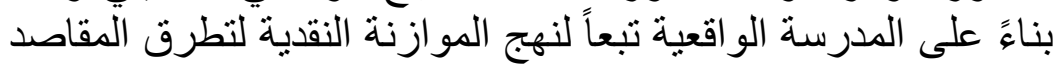

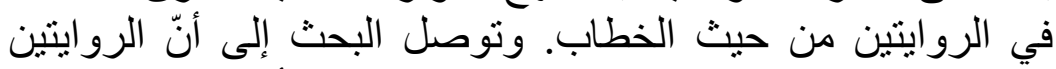

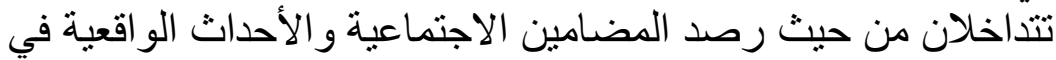

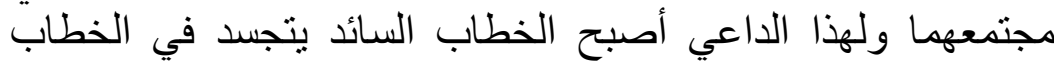

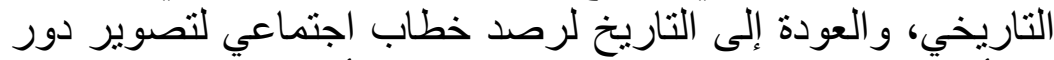

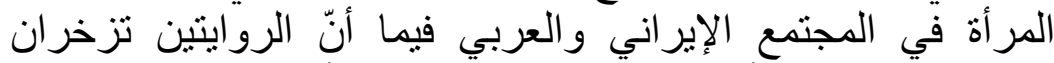

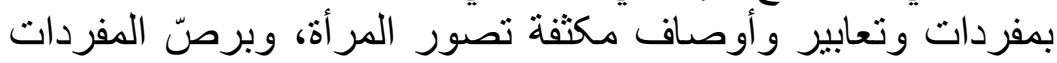

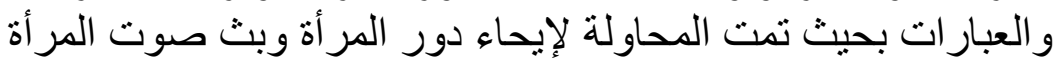

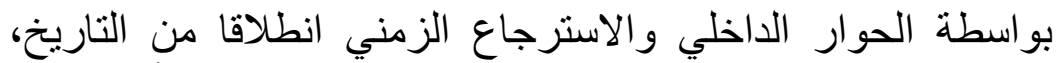

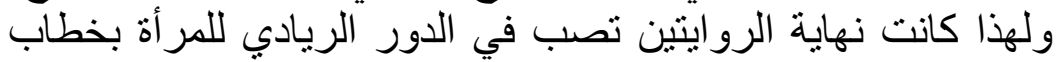

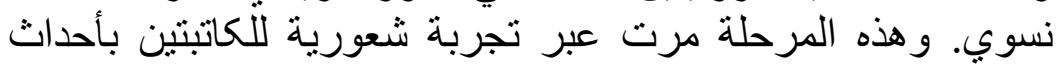

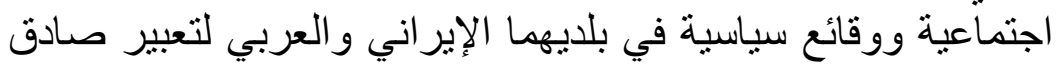

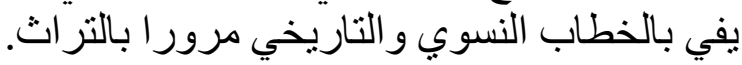

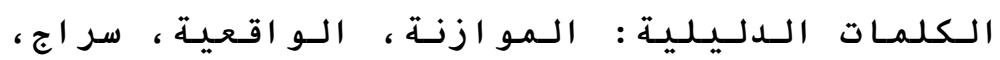

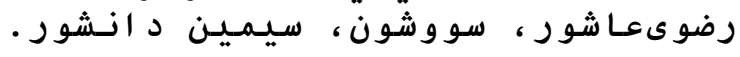




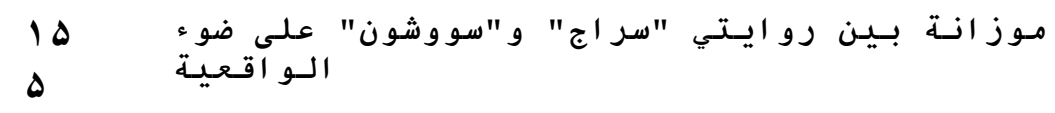

\section{المقدمة}

بات القرن المعاصر على مشارف التطور الاجتماعي من حيث الحركات الاجتماعية والنهوض بالتعبير عن دور كل من الوظائف الاجتماعية،

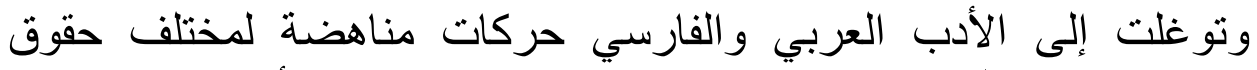

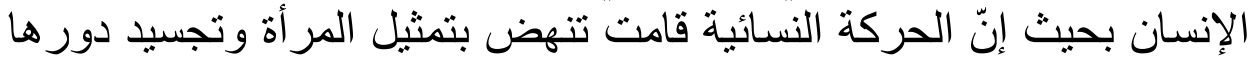

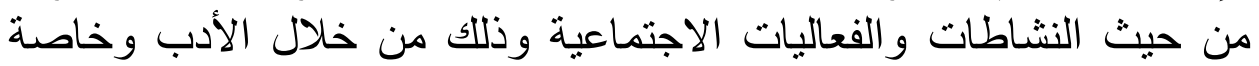

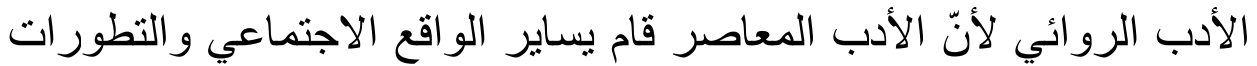
الاجنماعية والسياسية، ومن هذا المنطلق عرف الأن ألدبان العربي والفي الفارسي

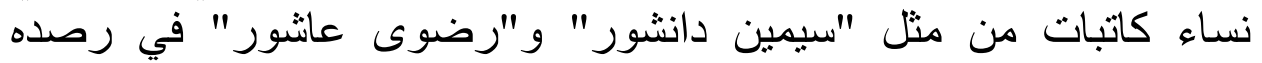

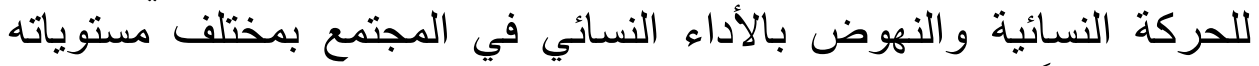
وذللك انطلاقاً من الرواية واية.

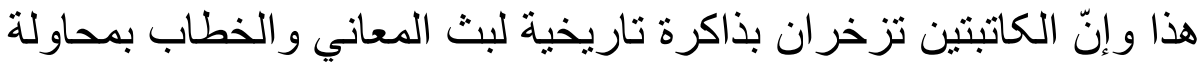

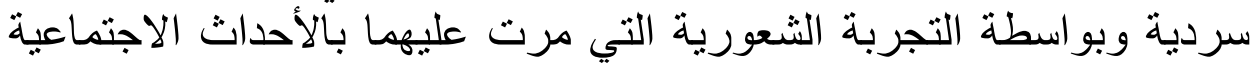

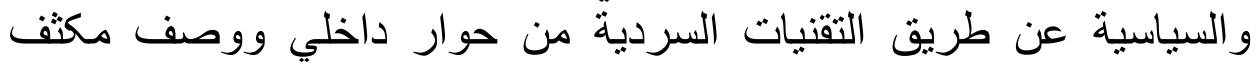

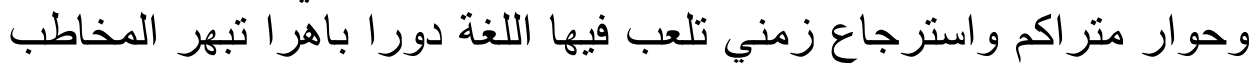

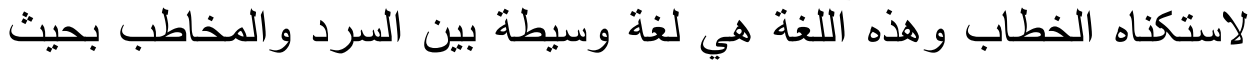

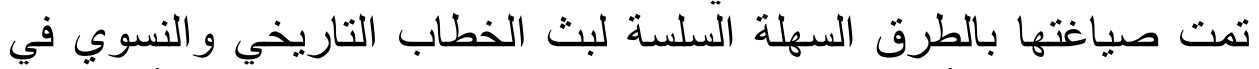
الروايتين بحيث تأتي ضروة البحث لفهم الطاقة الكامنة في المرأة الكانة الكاتبة باستغلال الكتابة السردية و الروائية بلغة سهلة وسلة التهة قريبة من فهم جميع

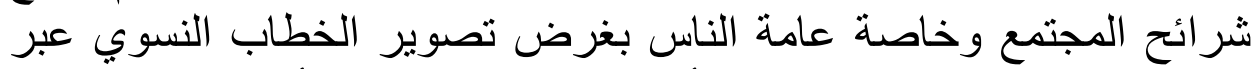

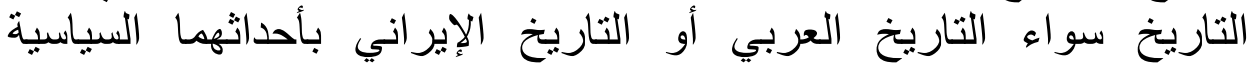
و الاجتماعية.

هنالك دراسات نذكر ها فيما يلي عالجت رواية "سووشون لسيمين

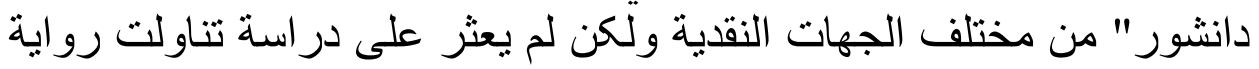

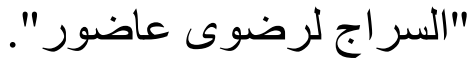

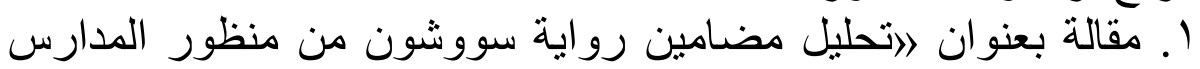

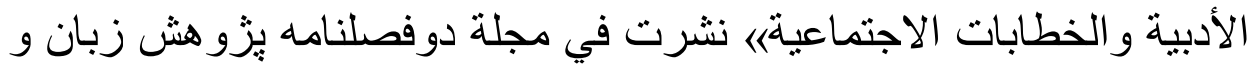

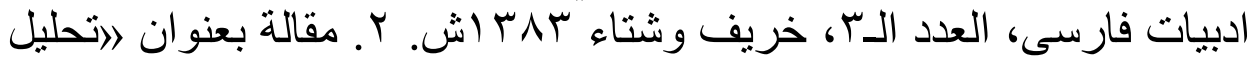

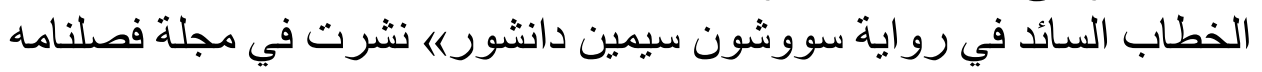




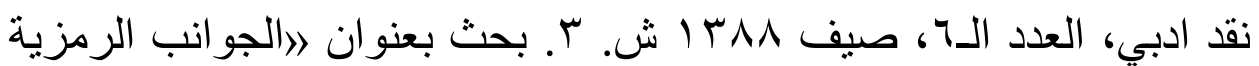
لرواية سووشونها نشر في مجلة فنون ادبي جامعة أصفهان، العدد الـا ، ربيع

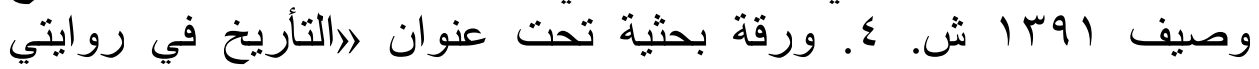

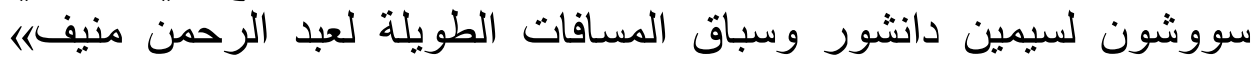

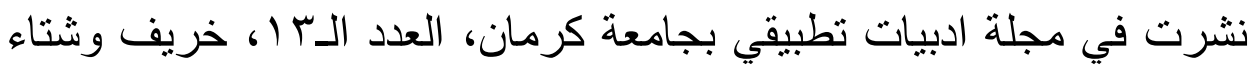

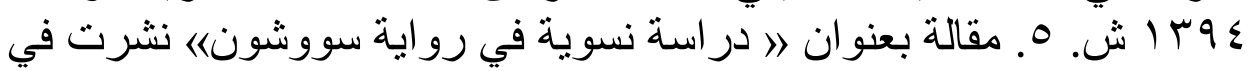

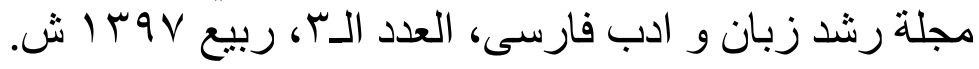

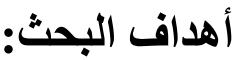

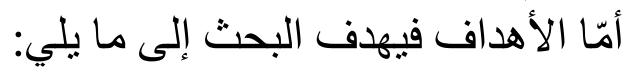

ا ـ الوقوف على وجوه التداخل لدى الكاتبات في العالم العربي وإيران.

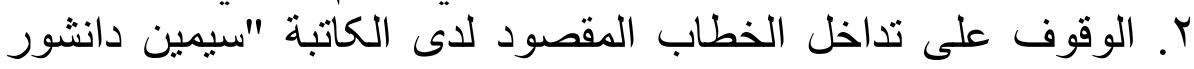
ورضوى عاشور".

\section{منهج البحث، الأسئلة والفرضيات}

بنتهج البحث المنهج الوصفي التحليلي وذللك بناءً على المدرسة الواقعية تبعاً لنهج الموازنة النقدية لتطرق المقاصد في الروايتين من حيث الخطاب.

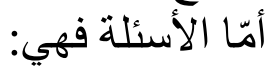
ا ـ ما هو تداخل الروايتين؛

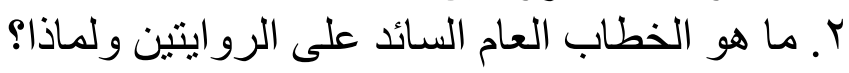
وبناءً على السؤ الين فالفرضيتان هما:

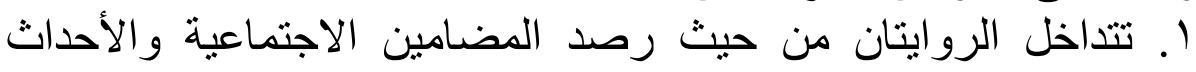

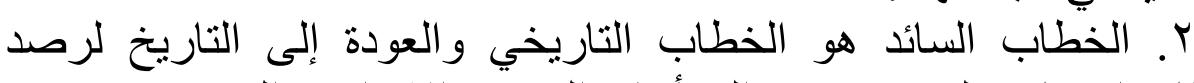

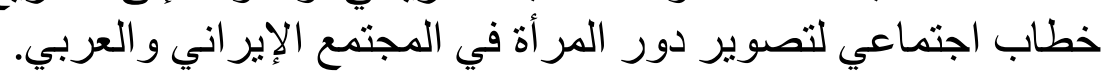
ا ـ نبذة عن الكاتبتين:

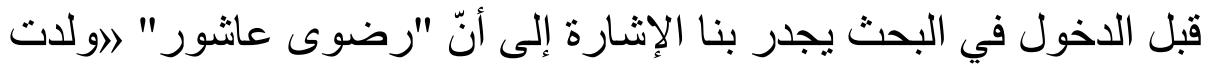

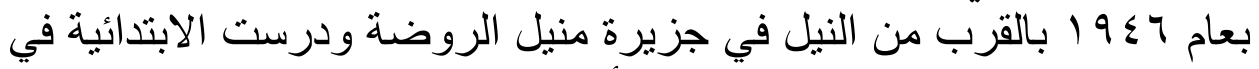

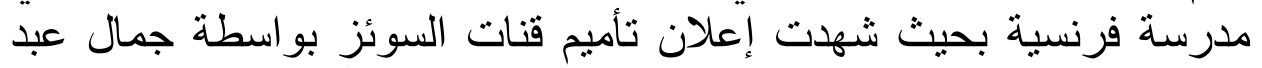

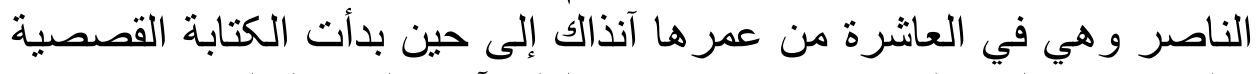

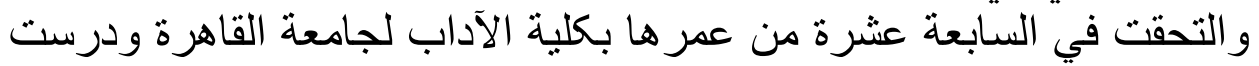

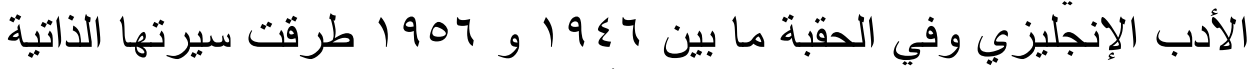

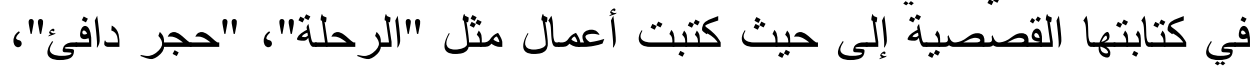




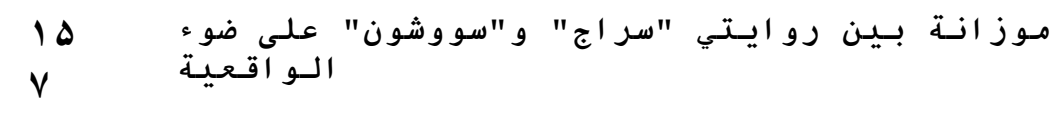

"خديجة وسوسن" ثم صبت اهتمامها في آخر أعمالها الروائية في رواية

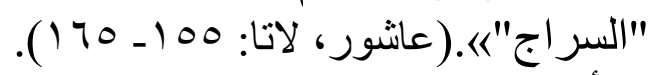

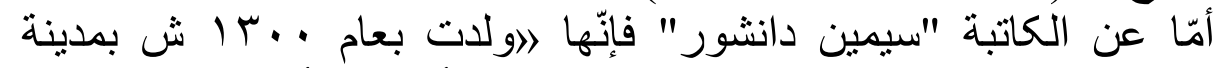

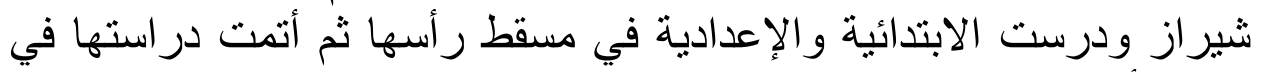

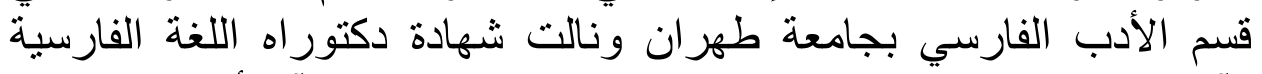
و آدابها حيث نزوجت مع الكاتب الإيراني الثهير جلال آل أحمد في العقد أندان

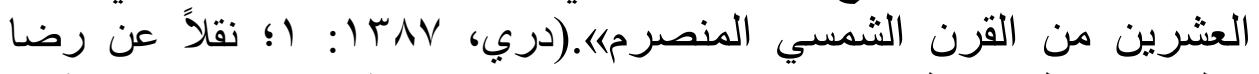

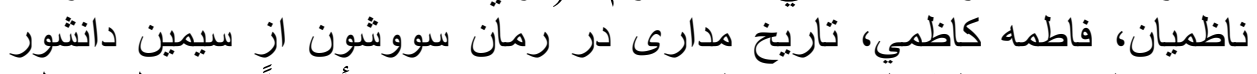

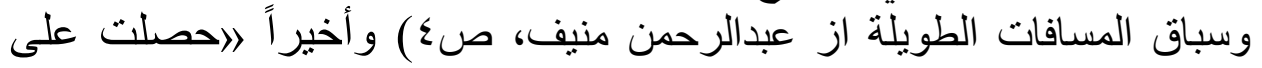

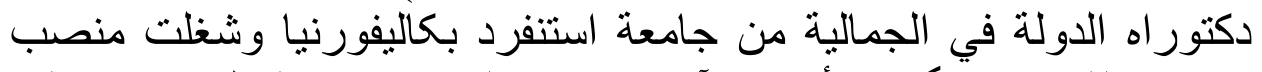

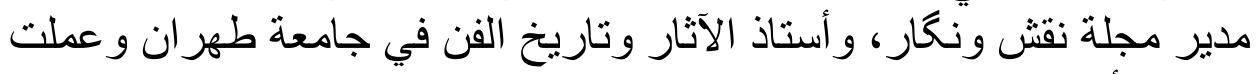

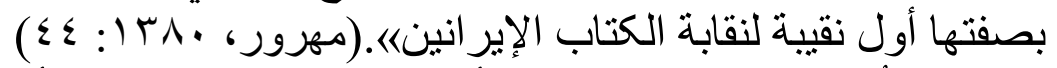

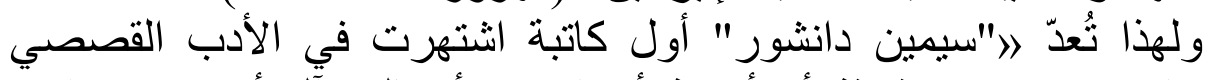

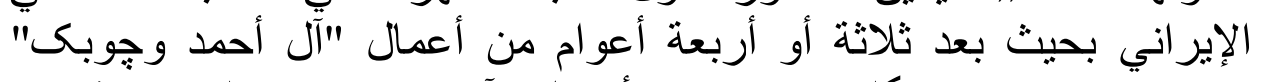

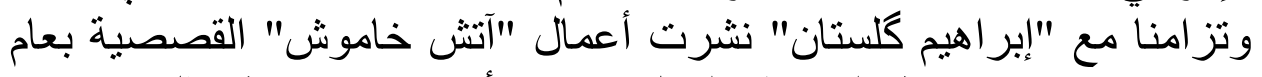

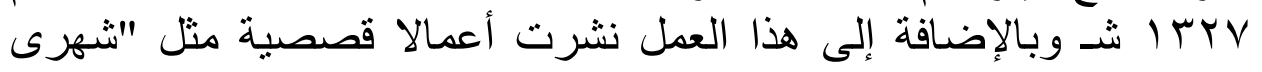

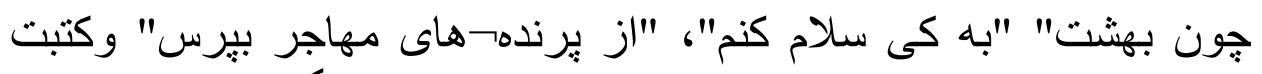

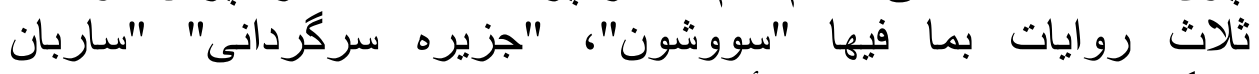

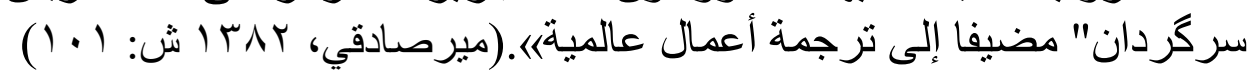

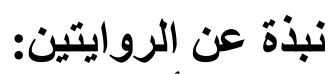

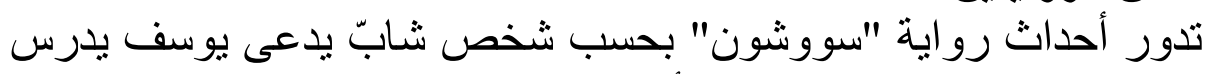

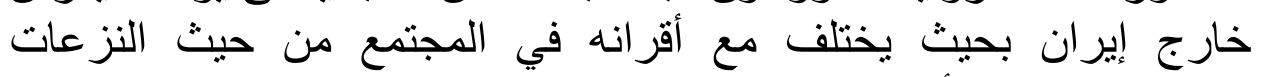
و الوجهات، ولهذا أثرت نز عاته ووجهاته في سلوكه وذللك بناءً على تعاطيه

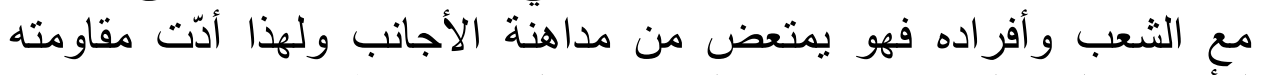

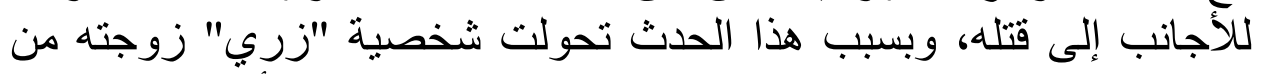

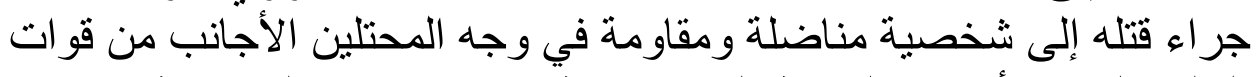

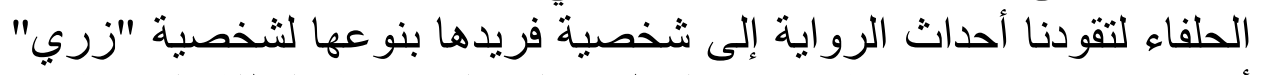

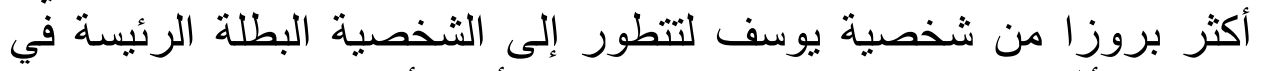

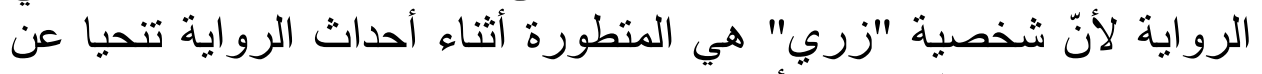

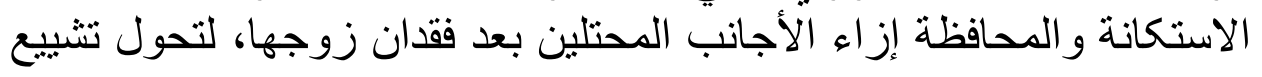




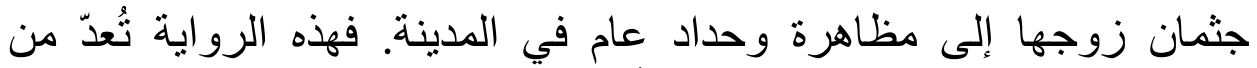

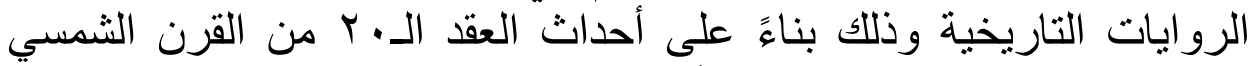

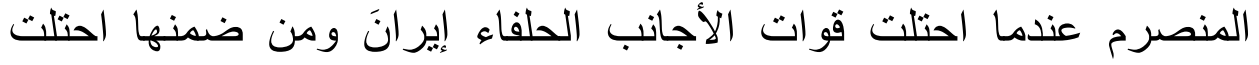
محافظة "فارس" من قبل القوات الإنجليزية فيما مهدت الطريت إلى الى كتابة هذه إنه

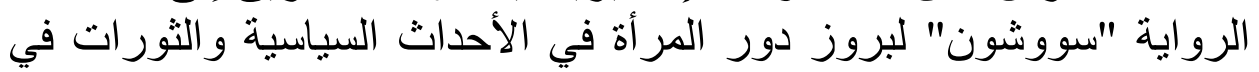
إيران. أمّا رواية "سر اج" فتبرز فيها لغة رضوى الراقيّة الأخّاذة وهي تتحدث

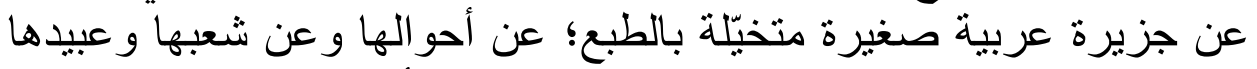

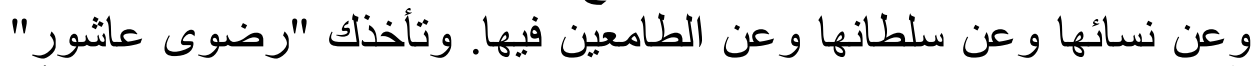

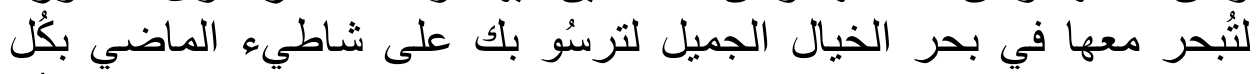

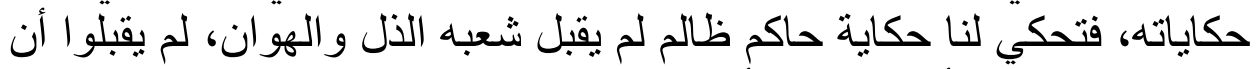
يتحكم في مصائر أبنائهج، وقد أحال ذللك الظالم حياتهم إلى جحيم، و استنزفهم

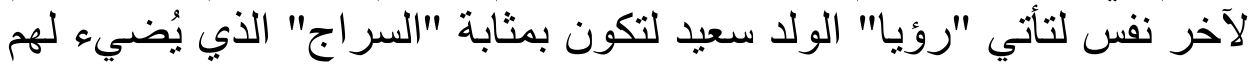

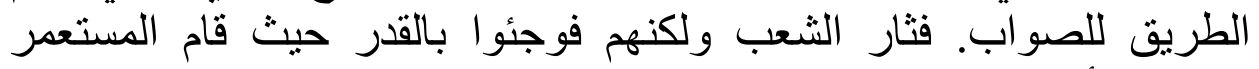
بحمايته و أحبط كل محاو لاتهم.

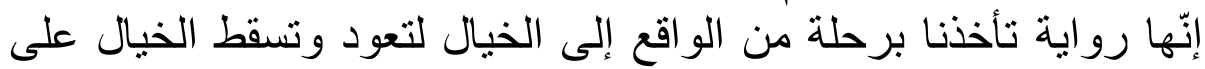

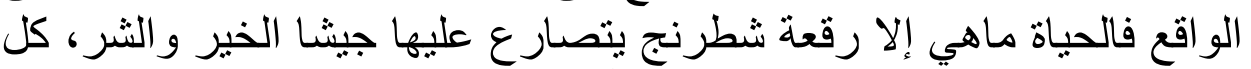

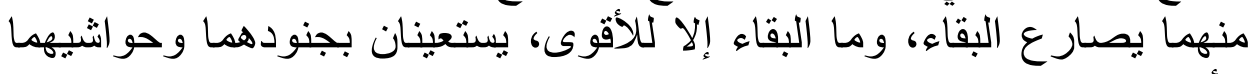

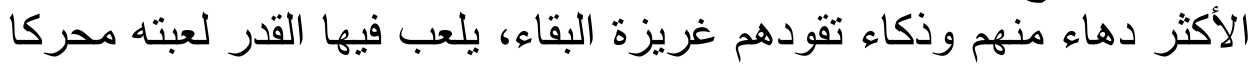

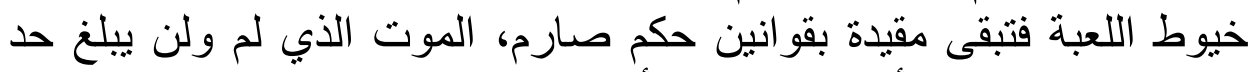
الاكتفاء مادام هنالك أغبياء يقدمون أرواحهم قر ابين ليصبحو اليحوا قنابل بشرية

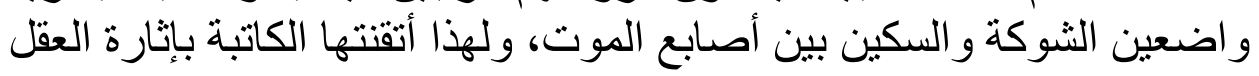

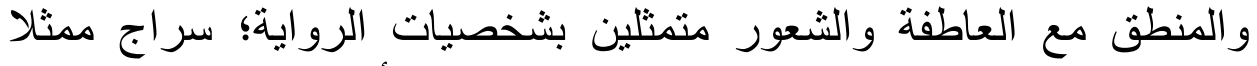

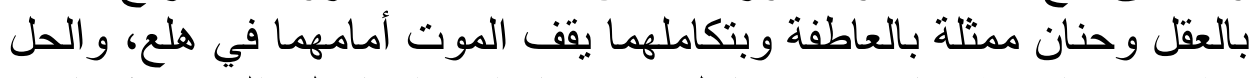

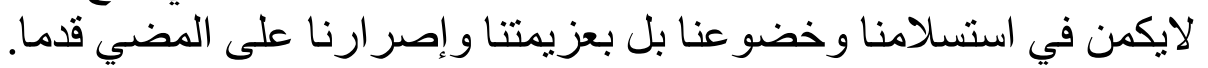

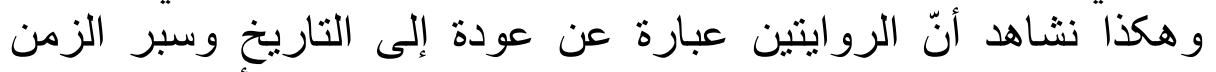

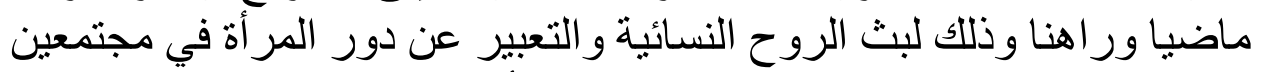

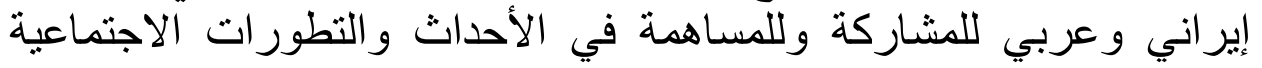

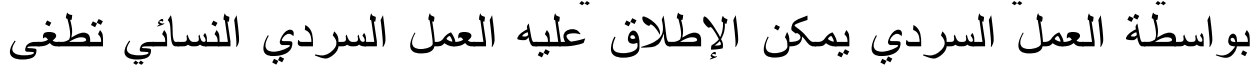
عليه الروح النسائية. r. الموازنة الواقعية: 
الموازنة بحسب المدرسة الأمريكية هي رصد أدبين مختلفين وذلك على المئى

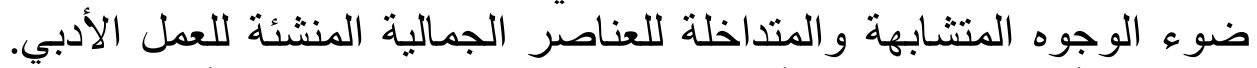

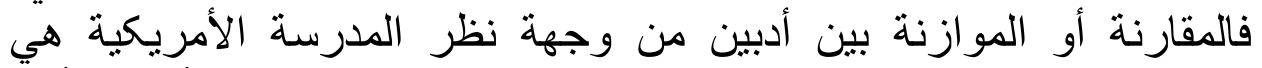

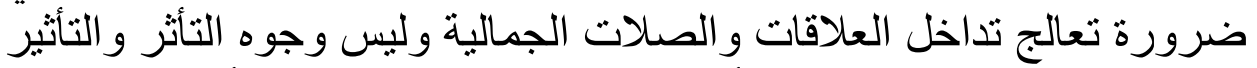

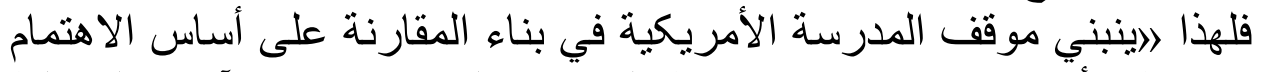

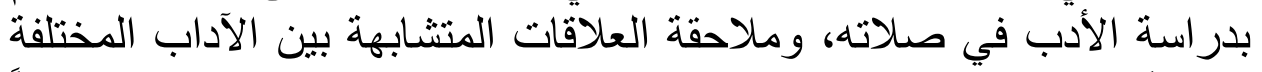

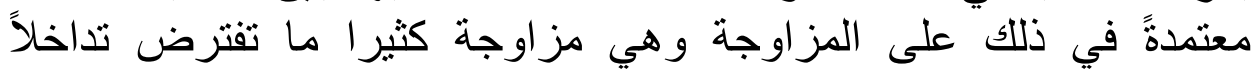

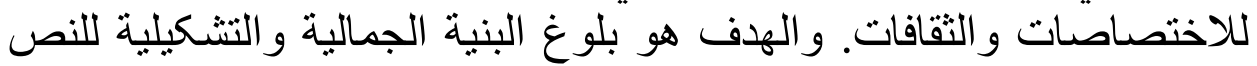

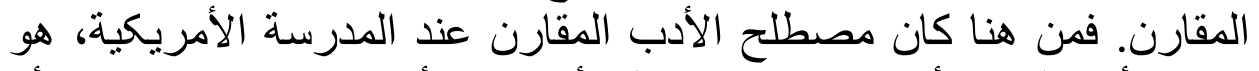

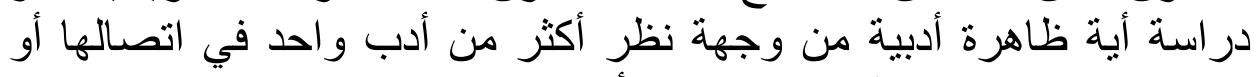

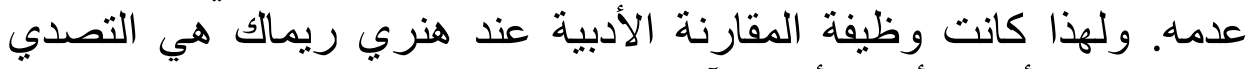

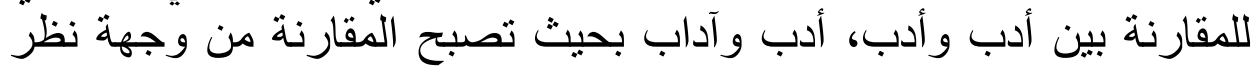

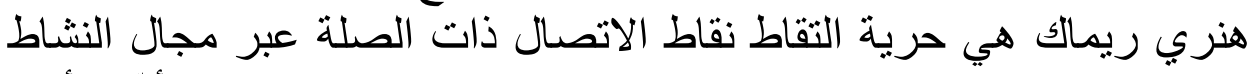

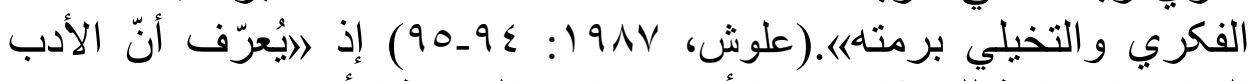

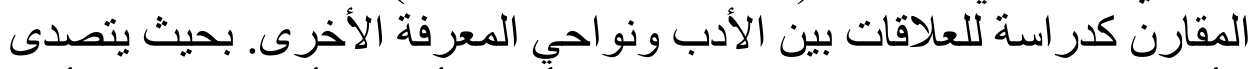

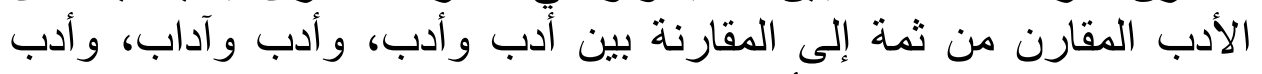

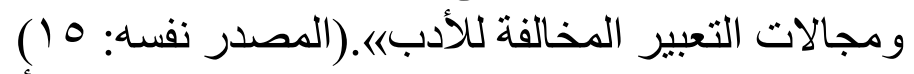

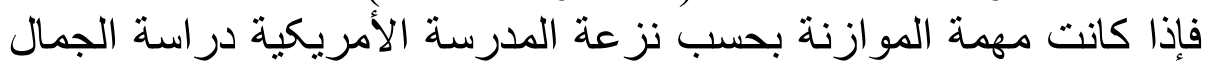

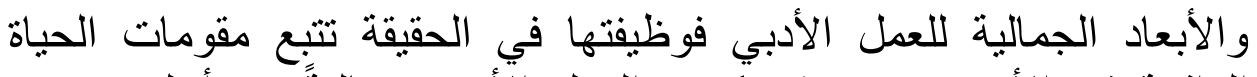

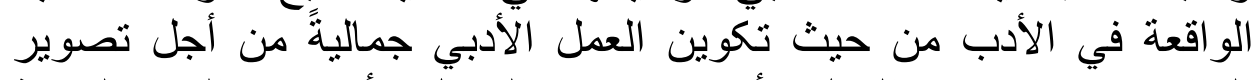

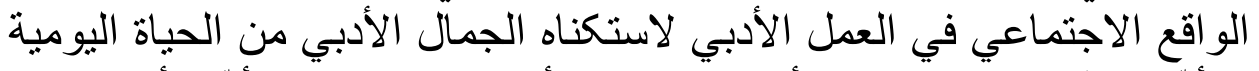

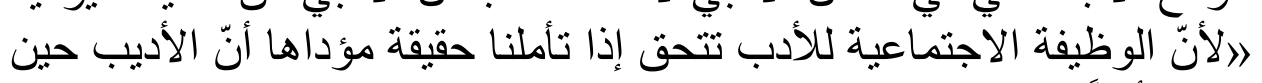

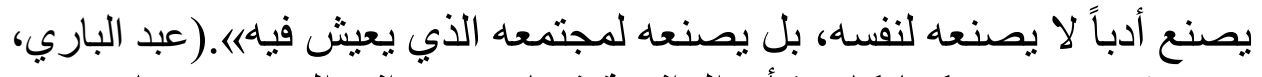

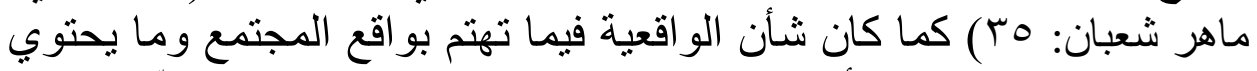

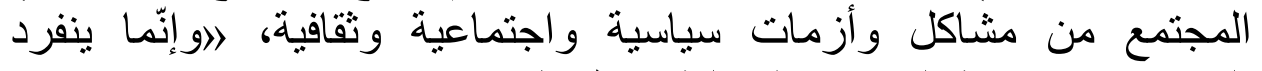

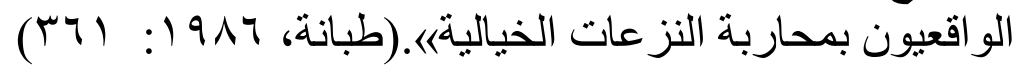

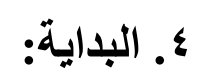

يعتمد النقاد على هذه الطريقة كقراءة بدائية للعمل الروائي انطلاقا من التهن

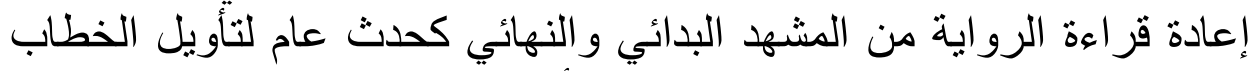

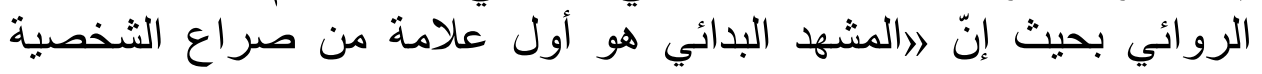


الرئيسة للرواية وهو سمة الروائية الدلالية فيما أنّ الروائي الحاذق هو الذي الذي الئي

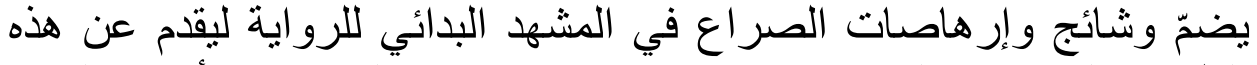

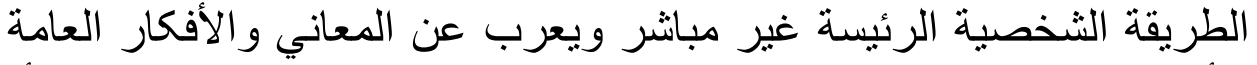

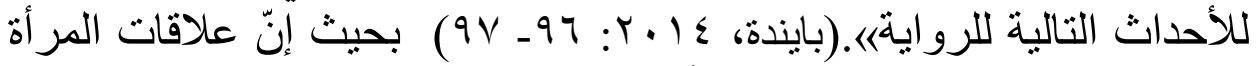

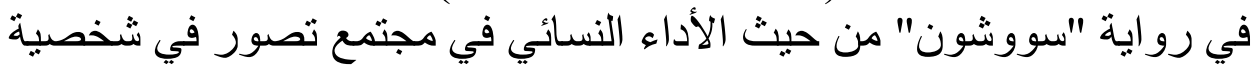

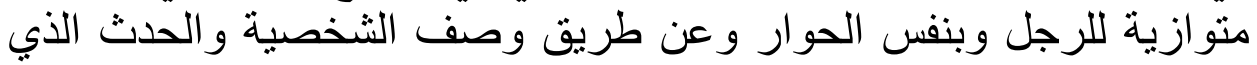

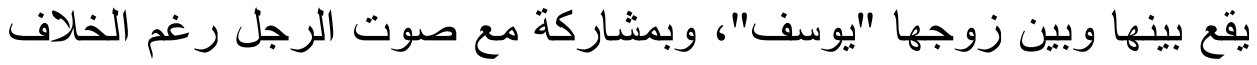
معه، ومع التركيز في الحفاظ على زوجها وتسليط الضوء الضو على المحافظة من

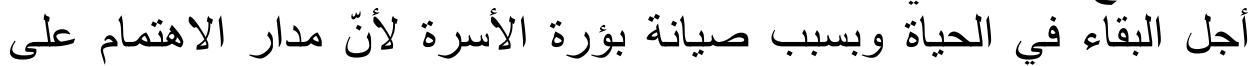

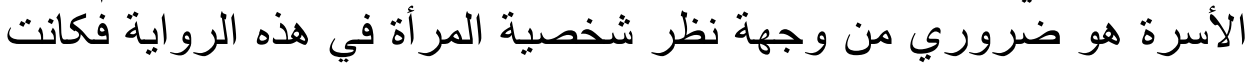

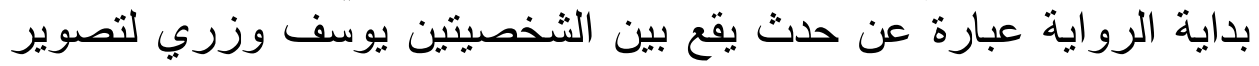

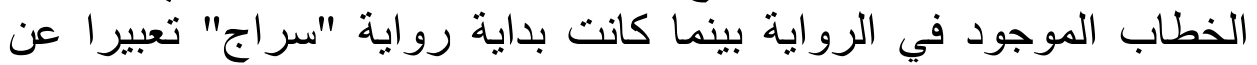

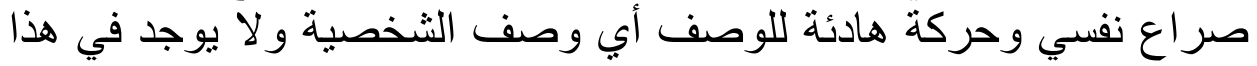

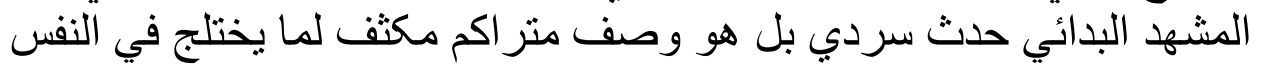
ويذوب في كامن الشخصية الروائية.

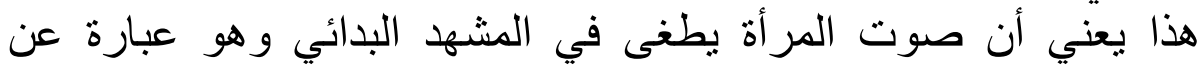
صوت واحد لا توجد لهذا المشهد مشاركة من قبل الرجل فئن فئن المشهد البدائي

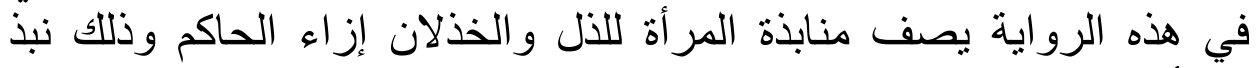

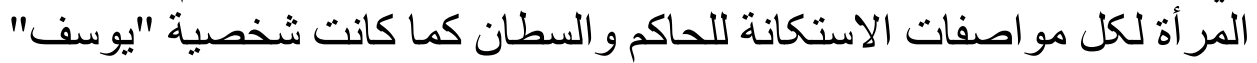

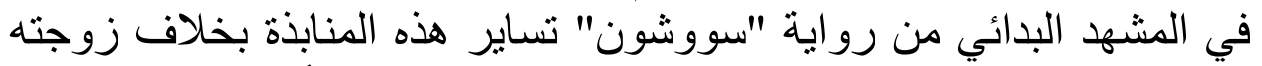

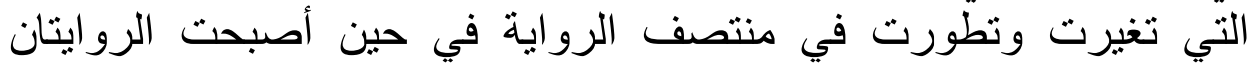

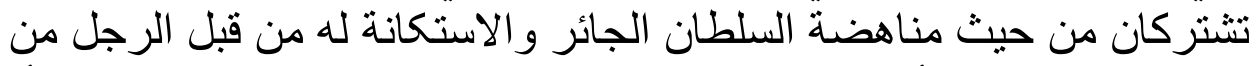

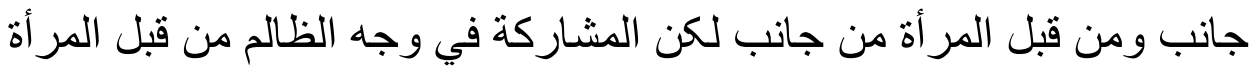

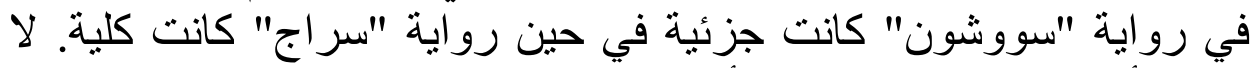

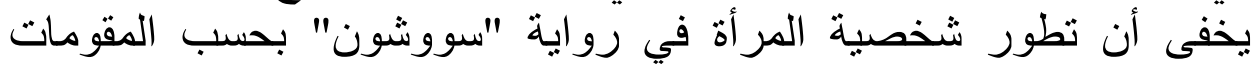

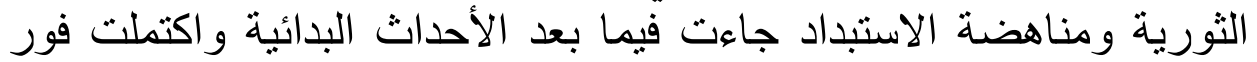

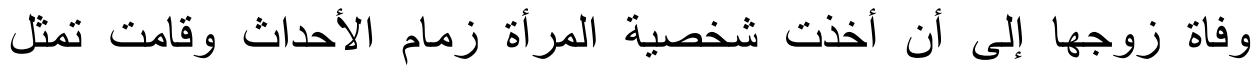
الشخصية البطلة رغم تأخر ها من حيث الوقوف في وجه الاستبداد. • ـ السرد الوصفي: تتم المشاهدة ونقل المحسوسات في الرواية عن طريق التسجيل والتقييد وذللك بواسطة الواقعيين عن طريث الوصف المثراكم بحيث إنّ الالمذهب فئ 


$$
\text { مـوز انـــــــن رو ايـتي "سر اج" و "سووشون" علـي ضوء } 19
$$

الو اقعي يدعو إلى تسجيل الملاحظات و المشاهدات من غير أن يُلِّونها الأديب

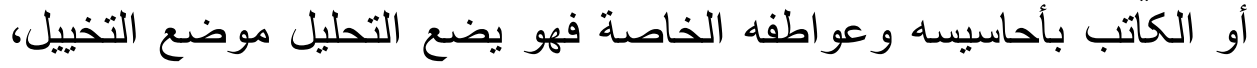

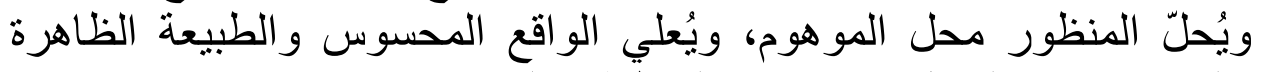

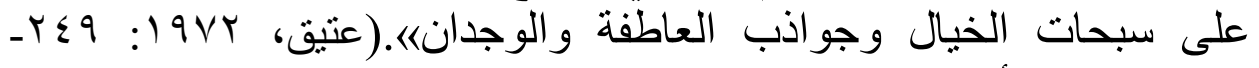

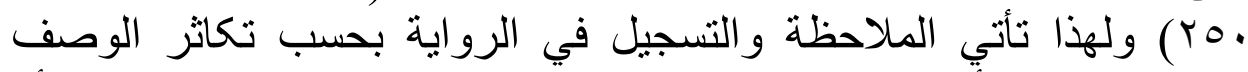

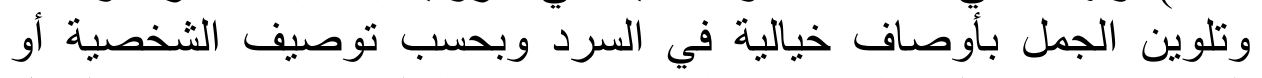

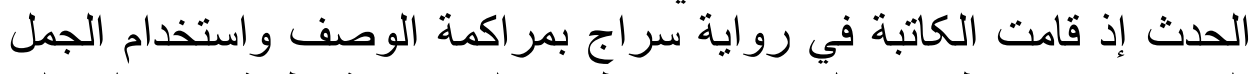

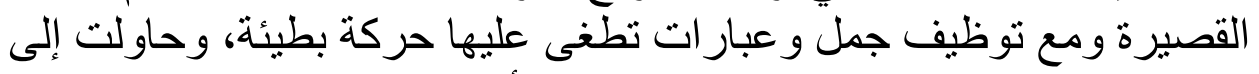

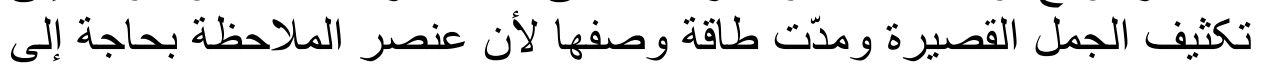

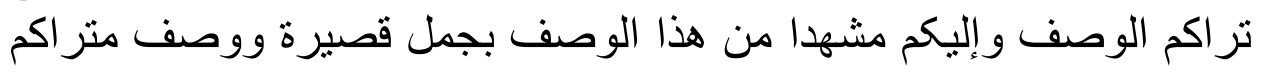
مكثف:

》افي الصباح اكتظت ساحة المطبخ بالنساء وقد انهمكن في الإعداد

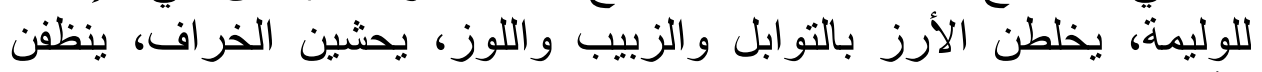

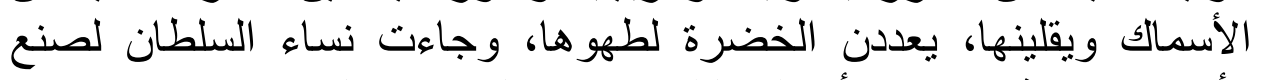

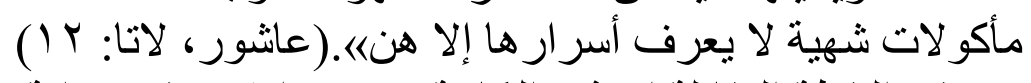

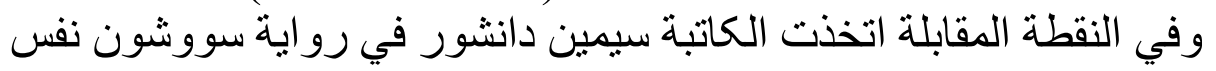

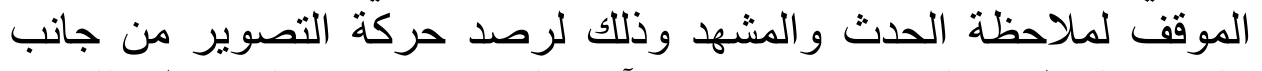

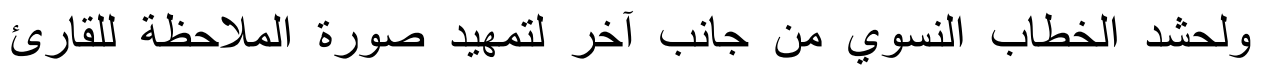

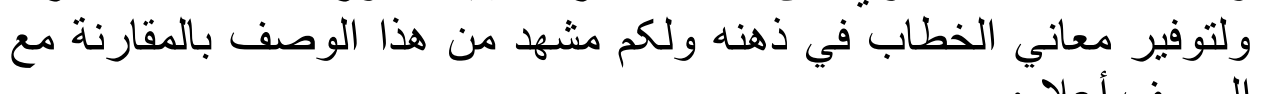
الوصف أعلاه: الالحاكم نفسه، طويل القامة، لديه أكتاف عريضة، شعره وشاربه أبيض،

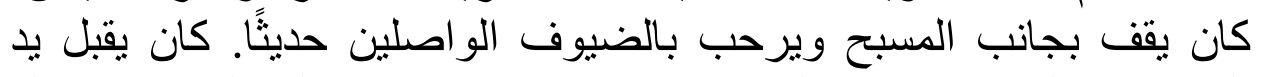

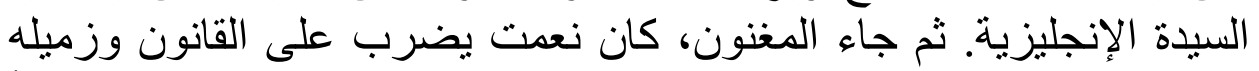

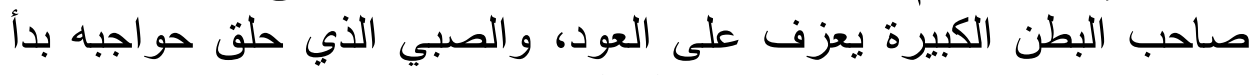

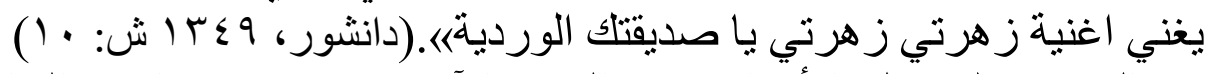

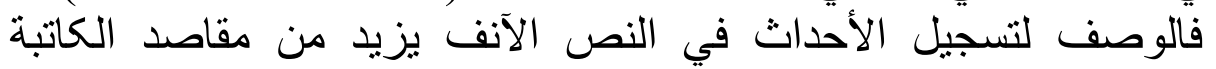

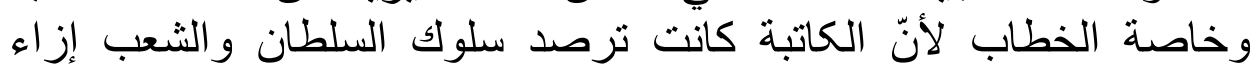

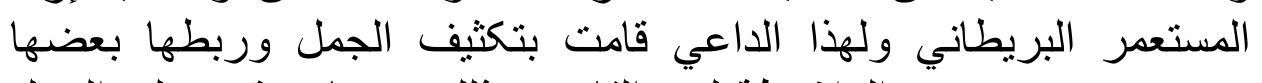

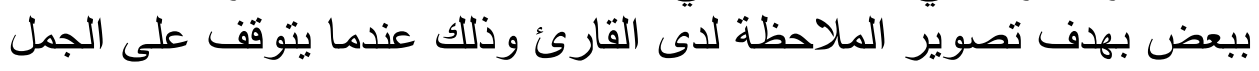

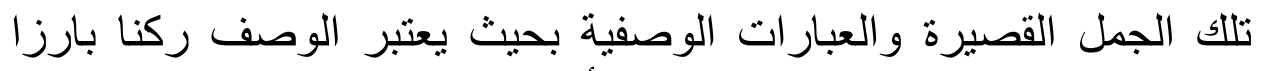

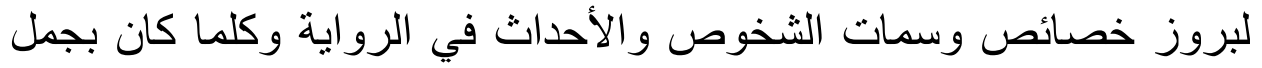


قصبرة ومقطو عات نثرية من الجمل المقيدة بالوصف والإضافة و غير ها من

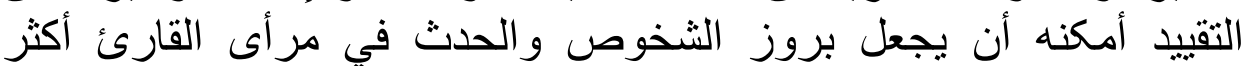

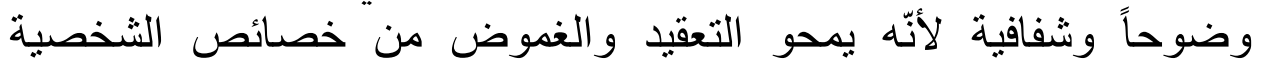

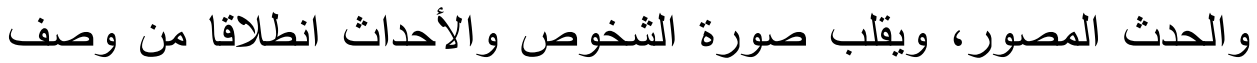
متكاثر متر اكم وذللك أنّ وصف الشخصية عبارة عن فكرة من أفكار السارد

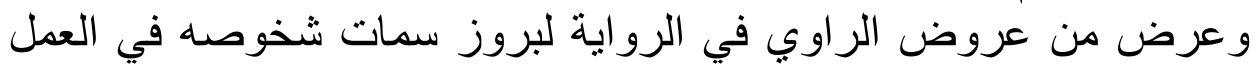
الروائي.

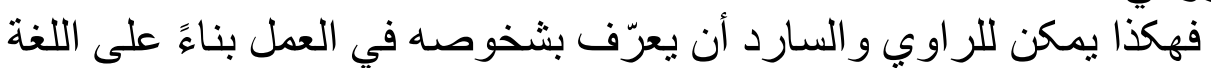

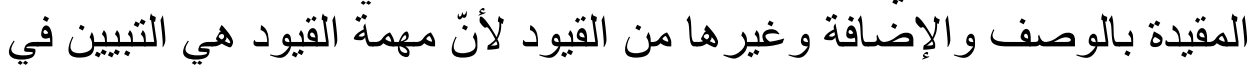

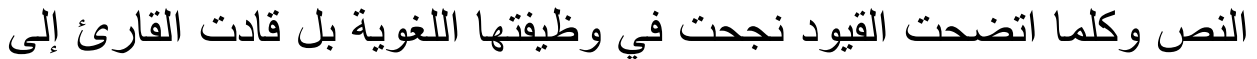
تشخيص الثخصية و الحدث الأكثر بروز آ في الرواية.

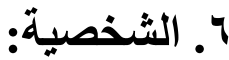

تعد الثخصية ركنا محوريا في الرواية وذلك لما تؤدي من حركة المسار

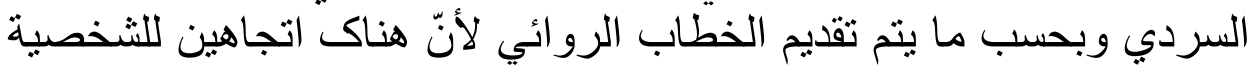

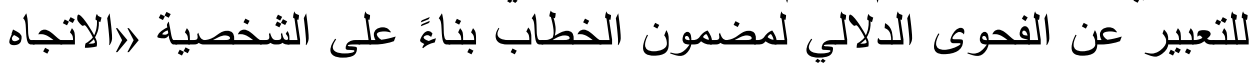

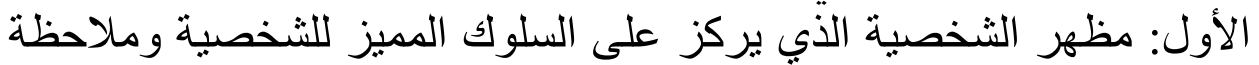
نشاطاتها المختلفة ملاحظة خارجية. الاتجاه الثاني: جوهر هر الثرية الثخية الثية الذي

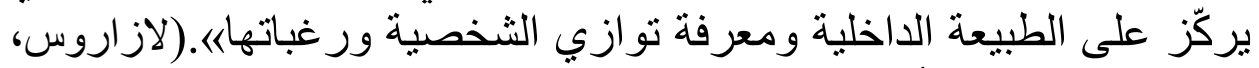

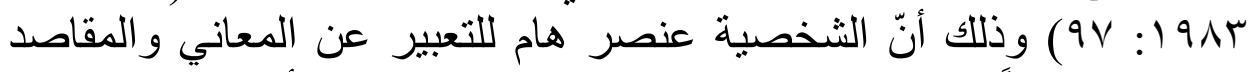

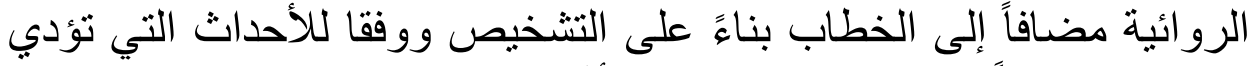

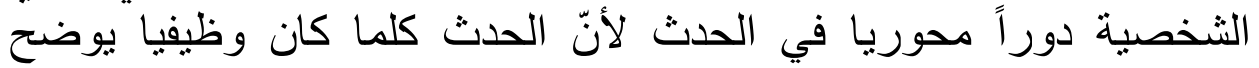
الخطاب وهذا يقوم على دور الشخصية ومدى مساهمتها في الحوار و والحدث

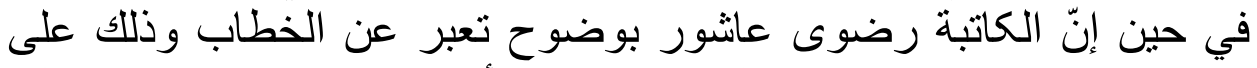
لسان الثخصية شخصية السطان الذي كان ألعوبة بيد الاستعمار والنية النظام الر أس مالي قائلا: >أنا الفقير الله تعالى نعمان بن خالد سلطان جزيرة غرة بحر العرب اتعهد

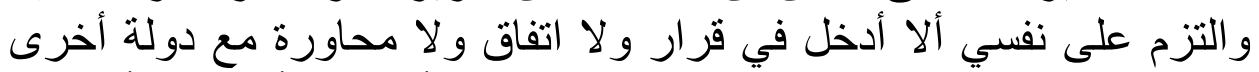

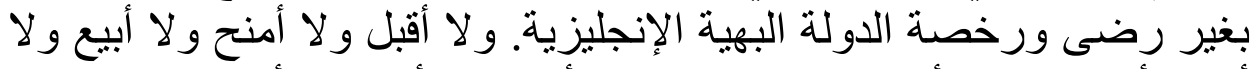

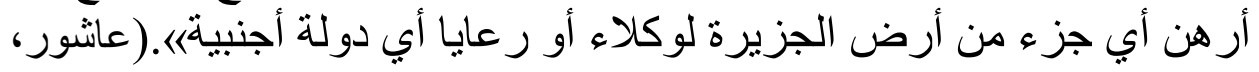




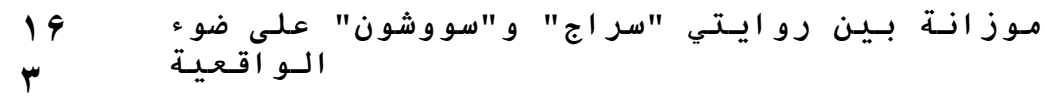

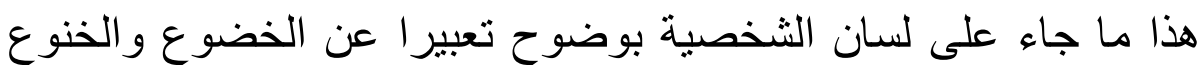

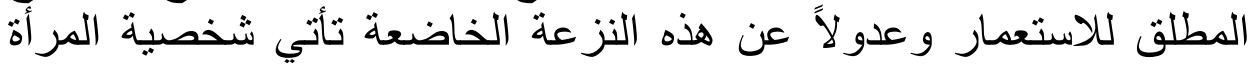
بالرفض التام تعبير ا عن ما جرى على لسان السلطان لمحاباة الاستعمار قائلة:

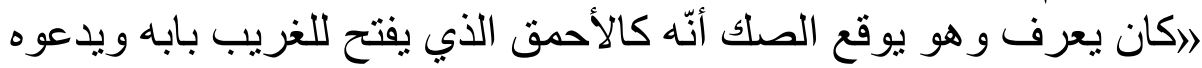

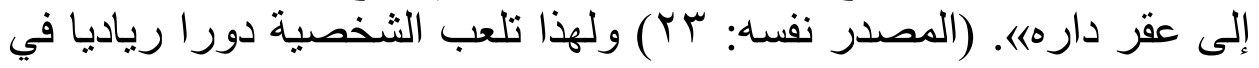

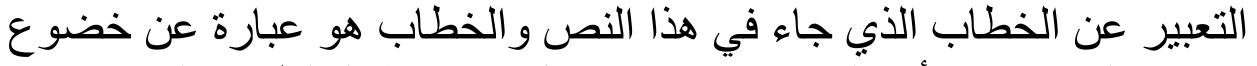

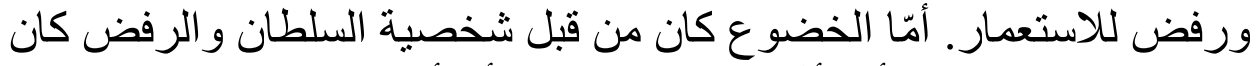
بواسطة شخصية المر أة لأنّ \الراويار اوي وسيلة أو أداة فنية يستخدمها الكاتب

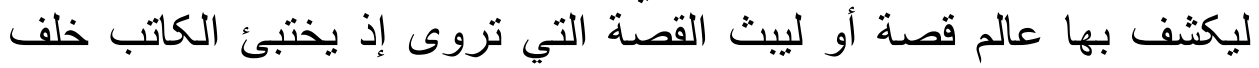

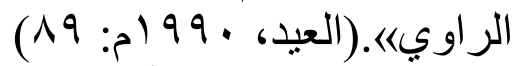

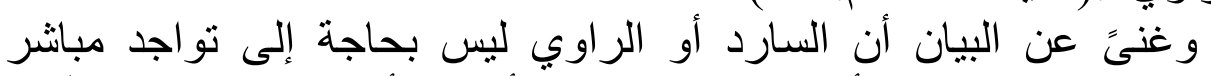

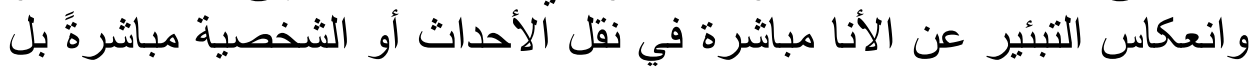

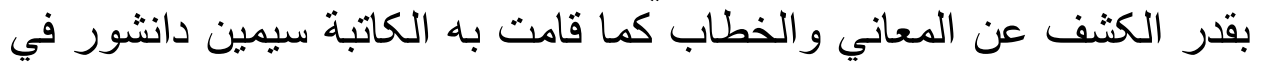
روايتها قائلة:

الايوجد التيفوس أو الخوف منه في كل مكان. ترى الرجان الرجال والنساء

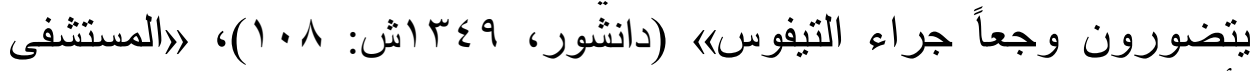

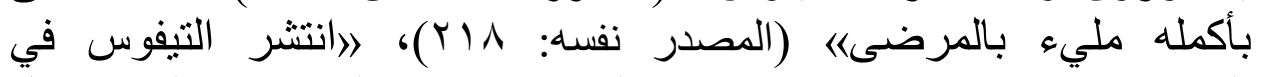

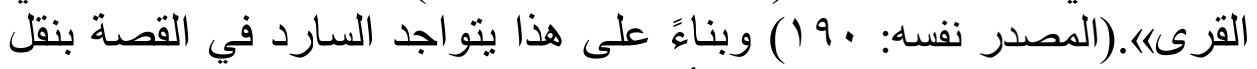

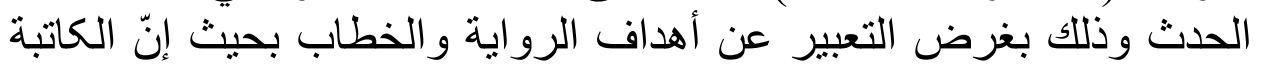

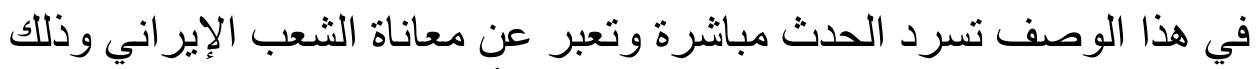

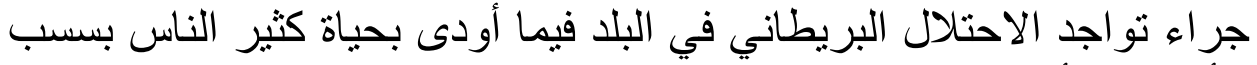

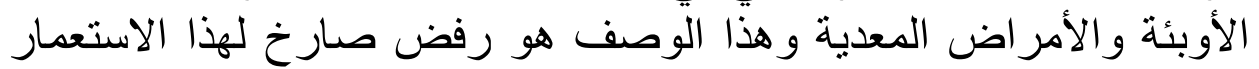

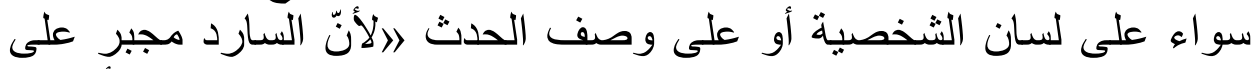

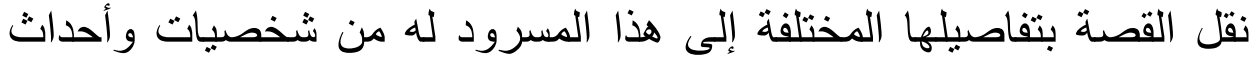

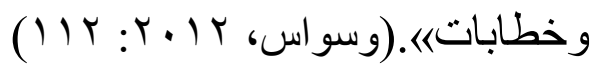

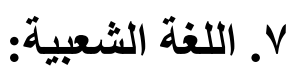

بعد أن مرّ الأدب العربي من العصر العبد العباسي والعثماني فسايرت اللغة

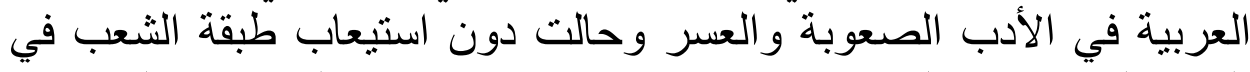

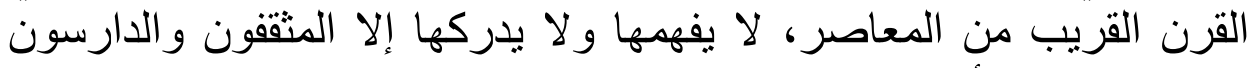

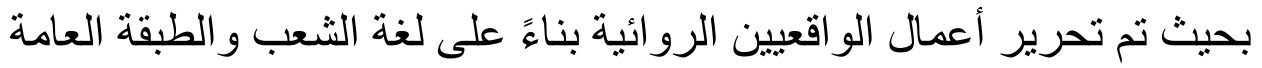


لتكون أيسر إلى استيعاب الناس بحيث إنّ الأدب الو اقعي \هو أدب لا يقتصر

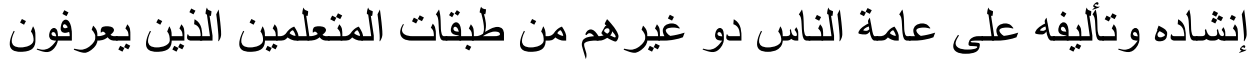

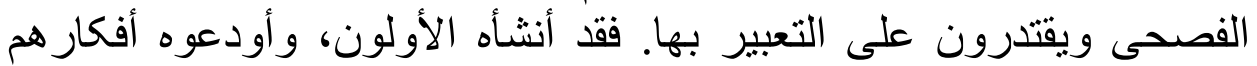
وتأملاتهم وحملوه عو اطفهم و انفعالاتهم ومشاعر هم بلغتهم التي يصطنعونها

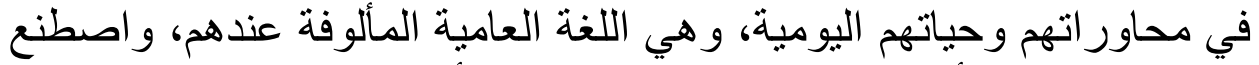

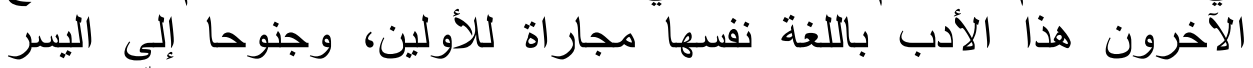

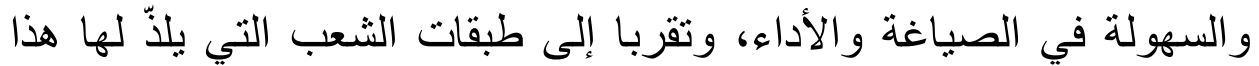

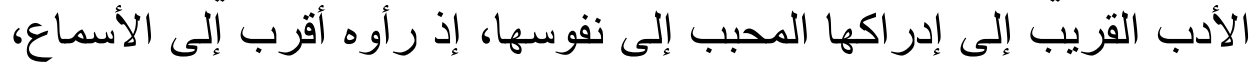

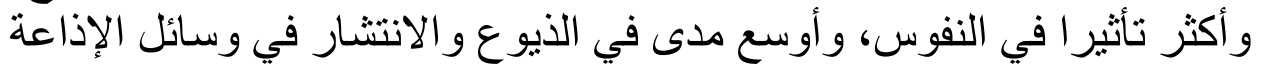

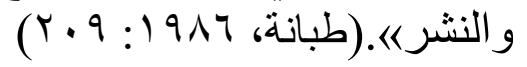

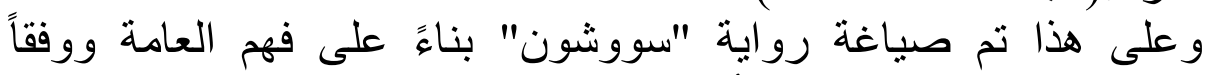

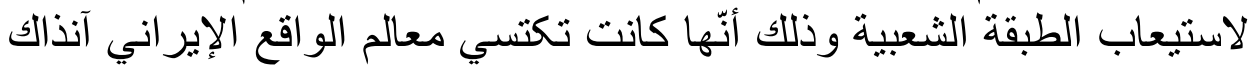

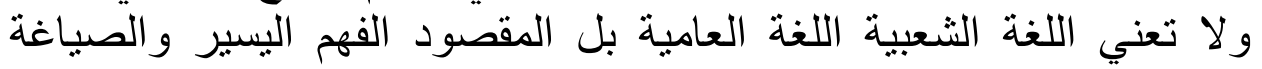
السردية بحسب الذوق الثعبي بلغة سهلة وبسيطة كما قامت الكاتهة الكاتبة بهذه

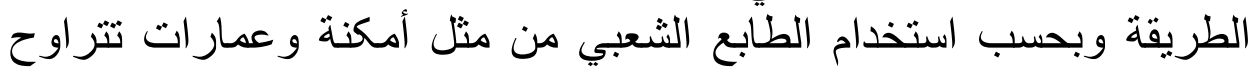

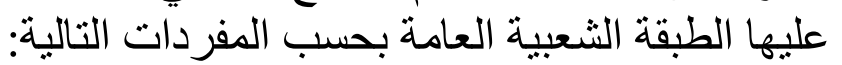

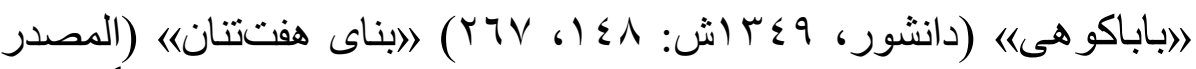

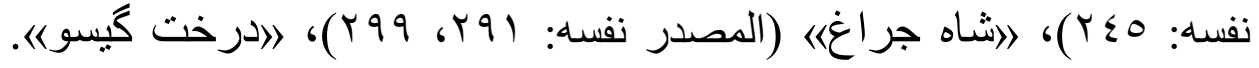

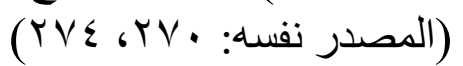

وهذه المفردات رغم قصر ها ومع إيجاز ها، عبارة عن عن ذاكرة تارة تاريخية وتعبير عن تراث ماضوي تتضوي تحت الذاكرة الثعبية تعيد القارئ إلى إنى

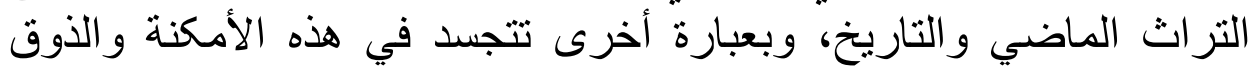

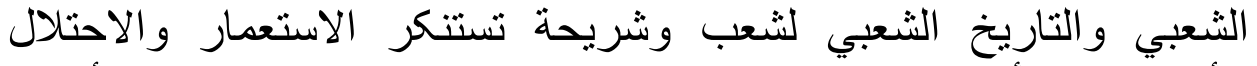
الأجنبي على أرضها، وبالتناسب لهذا تصف رضي رضوى الطاقة الثعبية بأكملها وتصورٍ سلوكا بسيطا للثعب وأعر اف شعبية يتناولها الجميع بحسب سذاجته و اصفةً:

ارأى عمار العبيد وقد افترشوا الأرض على شكل حلقة واسعة حول الساحة ور أى كومات من الحطب الموقد تحت دلات صغئ صغيرة قال لله سعبد إنّها

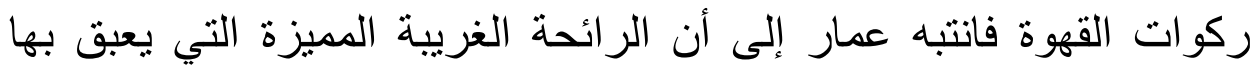

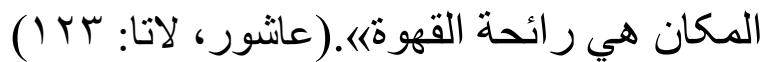

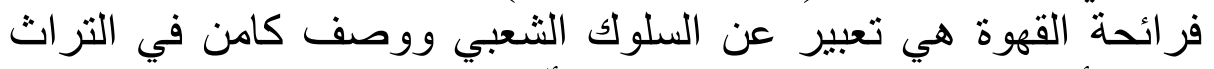

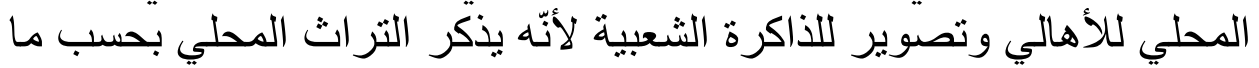




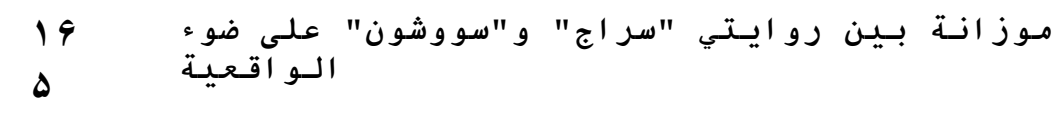

يجمع الجميع حوله، ويزيد من الحفاوة بين الجالسين، ويرفع الروح الأخوية الألية

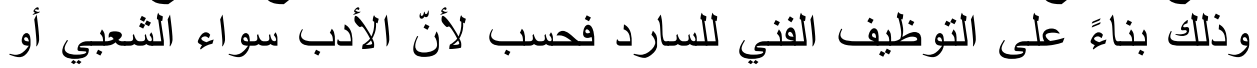

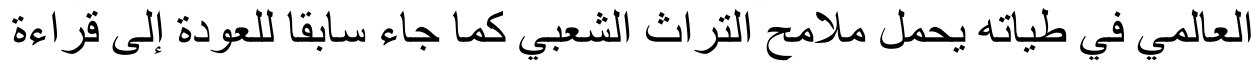

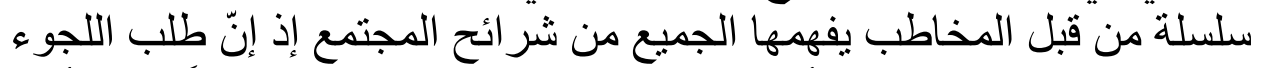

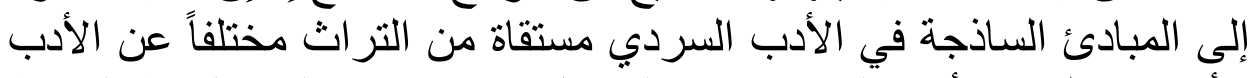

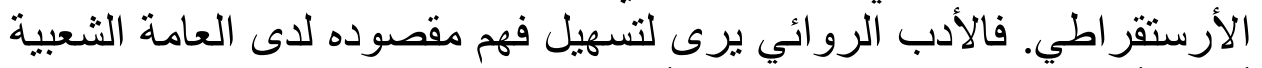

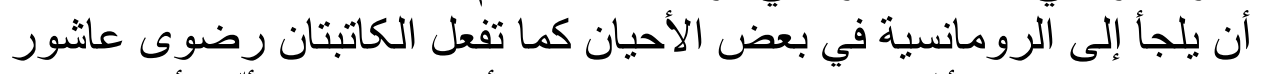

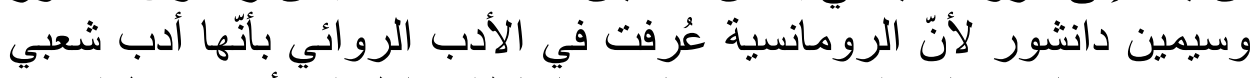

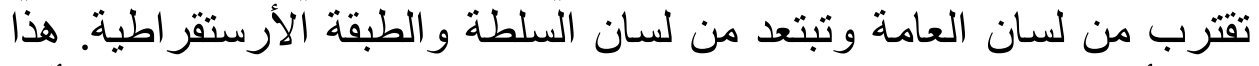

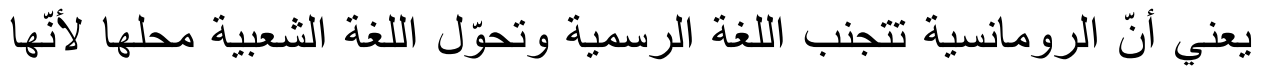

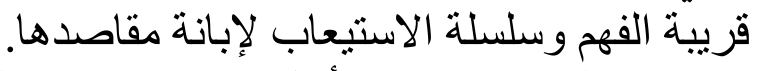

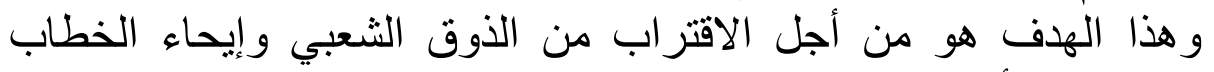

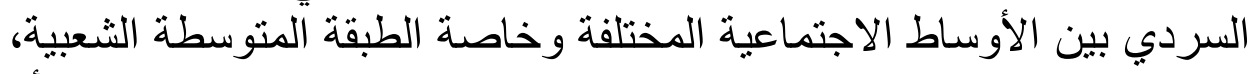

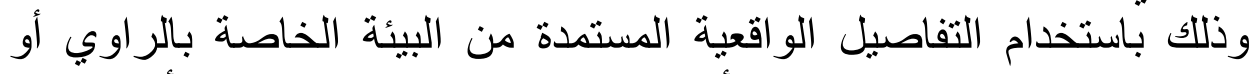

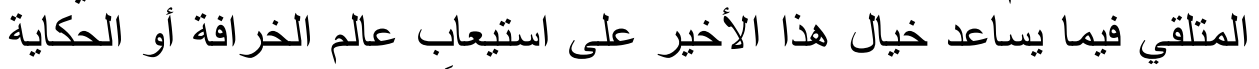

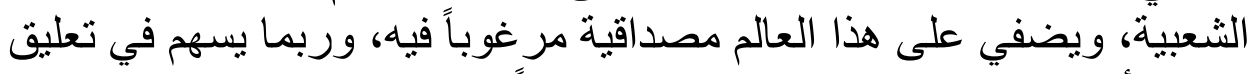
الحدث أو السمو بـه على الرغ عم من كونه عادياً.

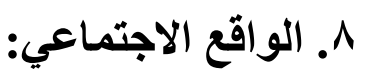

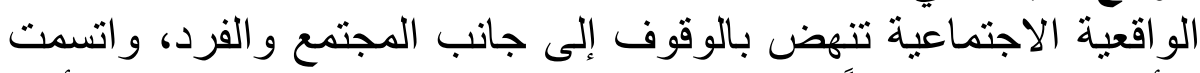

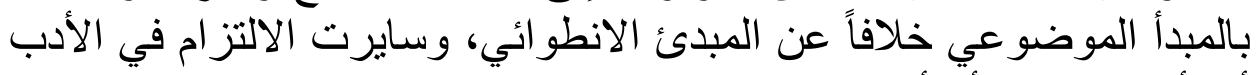

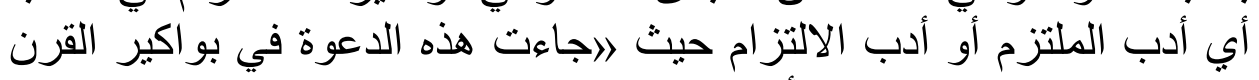

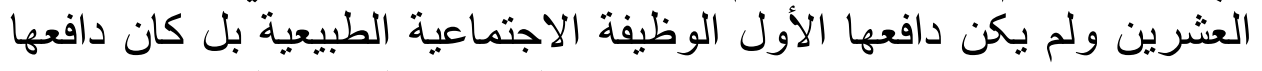

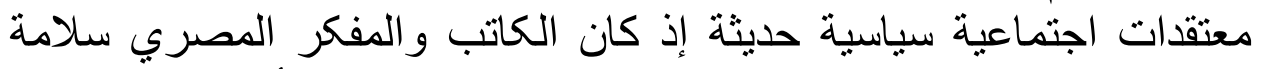

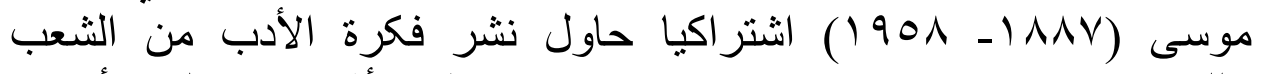

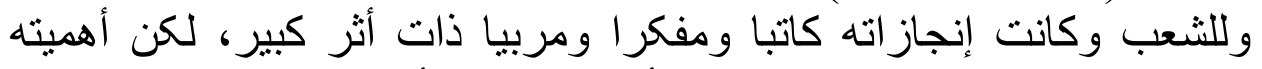

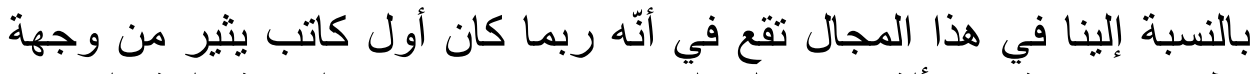

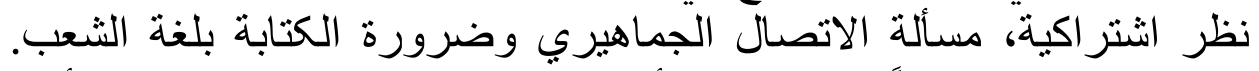

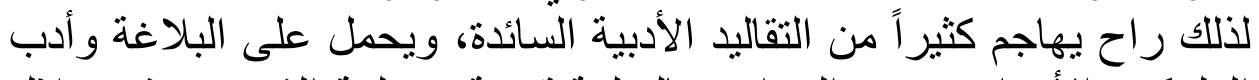

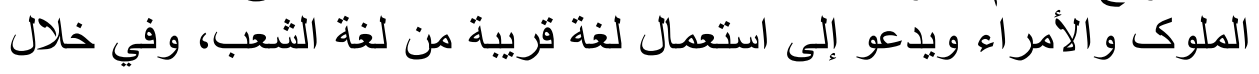


حياته كان يصر على فكرة الصدق في الأدب وعلى مقترب واقعي إلى (الى

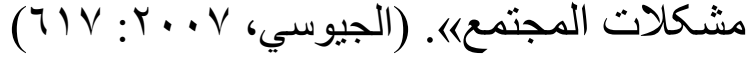

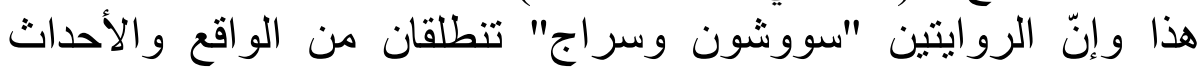

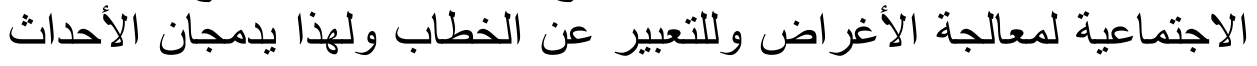

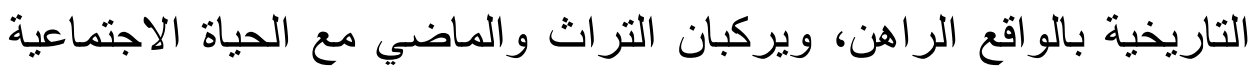

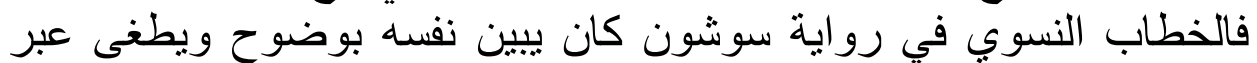

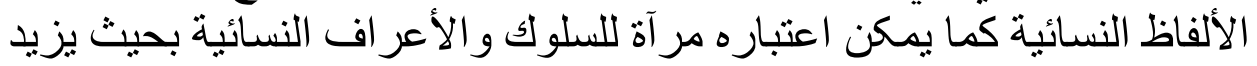

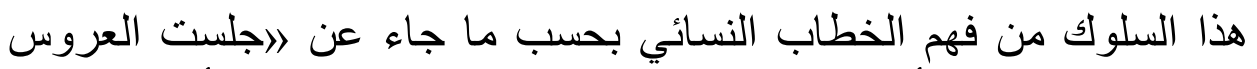

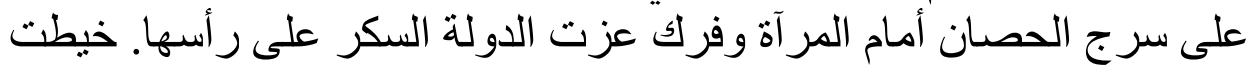

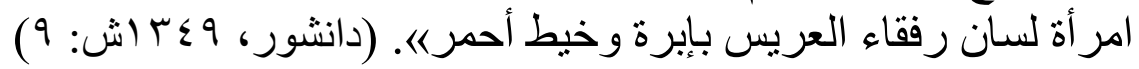

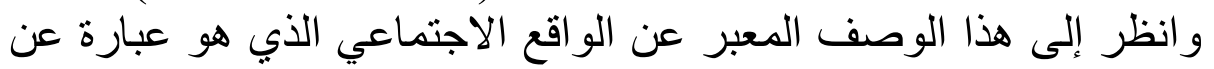

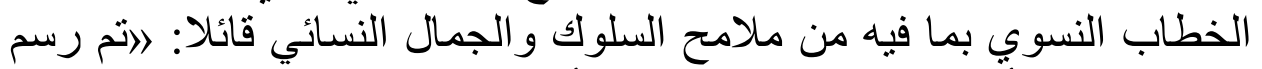

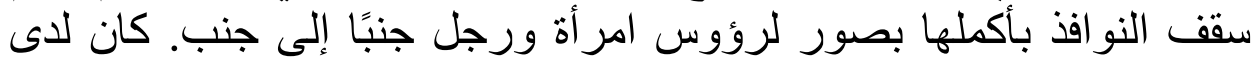

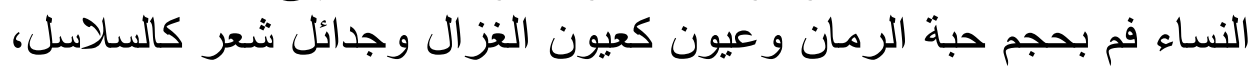

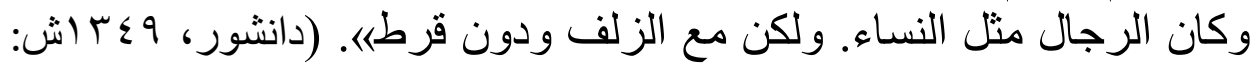

وبالتوازي مع هذه الملامح النسائية والأعراف التي ترتبط بالمرأة يأتي

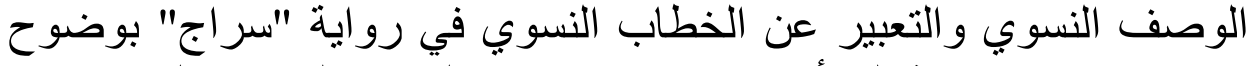

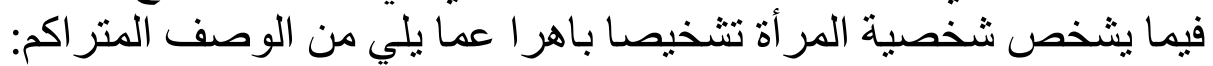

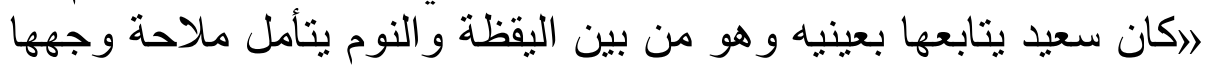
وطول قدها النحيل وشعرها الأسود المضفور كأذناب الخين الخيل رآها بهية

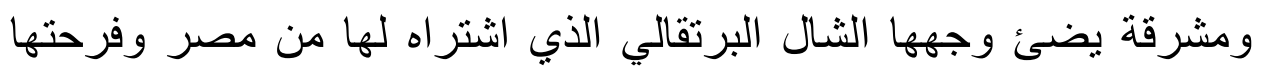

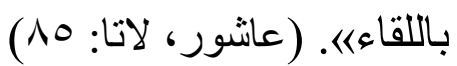

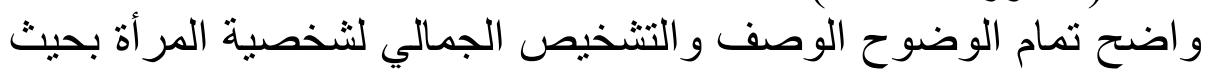

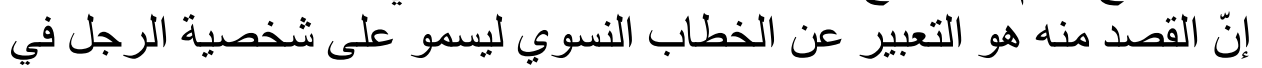
هذه الفقرة وذللك رغم جميع توازي الدور لكل من شخصية الرجل وشئ وشخصية

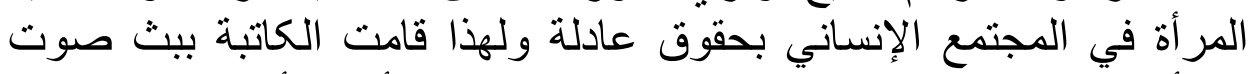
المر أة وذلك عن طريق تكثيف الصورة الإنيف الجمالية للمر أة من أجل بناء الخطاب

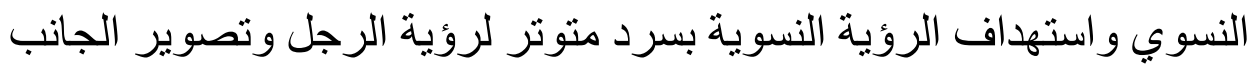

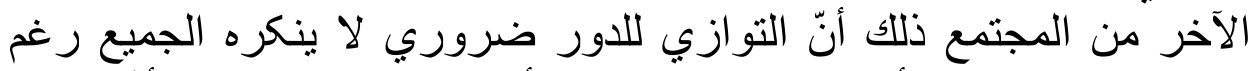

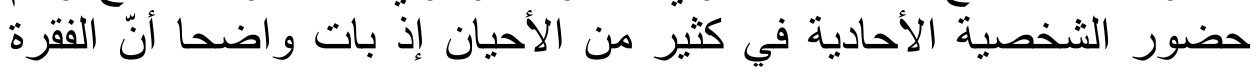
ترصد الخطاب النسوي وتحشر الدلالات النسوية وذلك عندما تبث الثان خطابها 


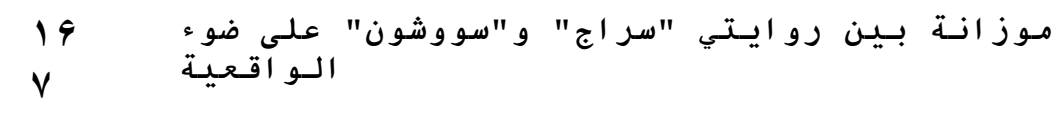

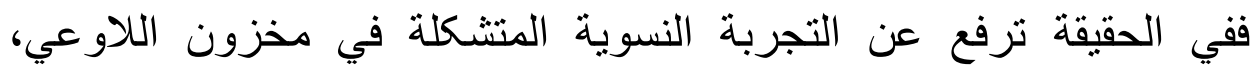

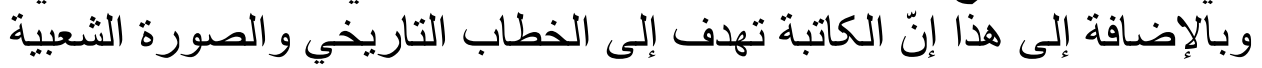

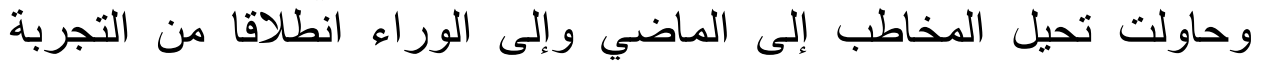

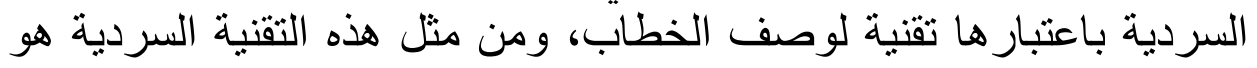

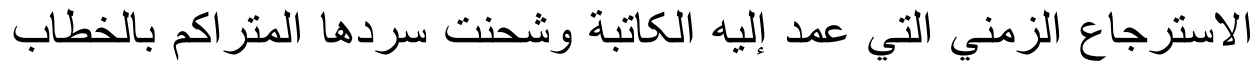

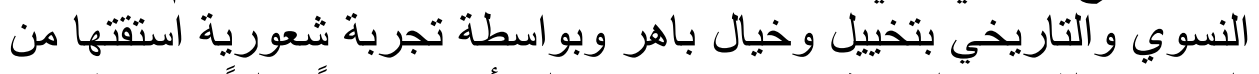

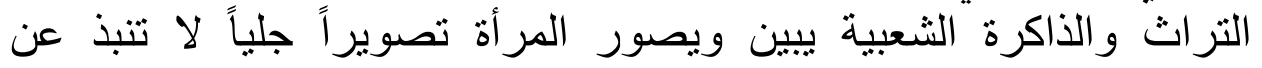

$$
\text { المجتمع الإير اني و العربي. }
$$

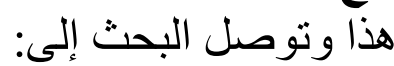

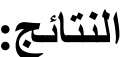

ا ـ أنّ الرو ايتين بالإضافة إلى سائر المعاني و الأغر اض من قومية وشعبية

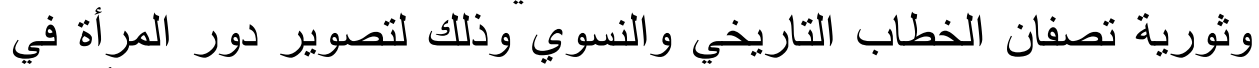

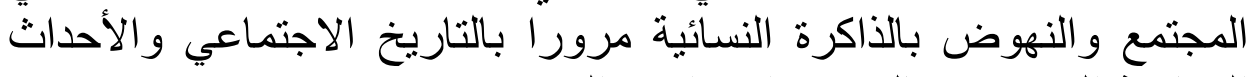

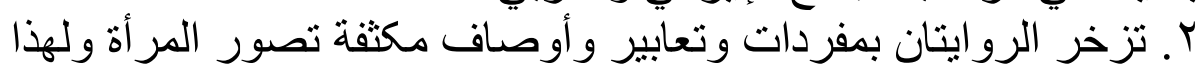

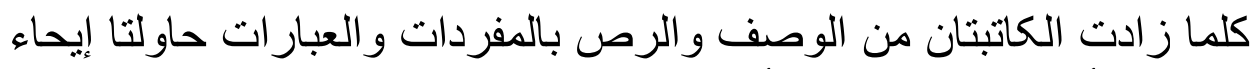

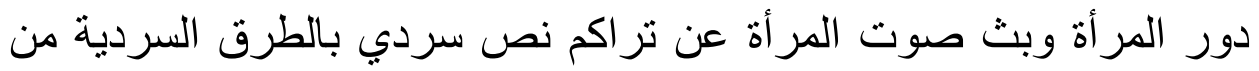

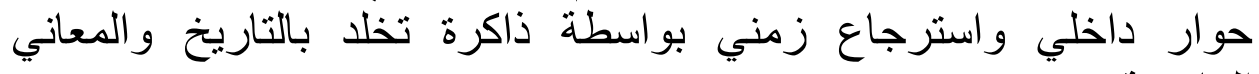

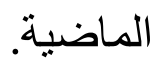
ץ. كانت نهاية الروايتين تصب بالدور الريادي للمر أة بخطاب نسوي و هذه

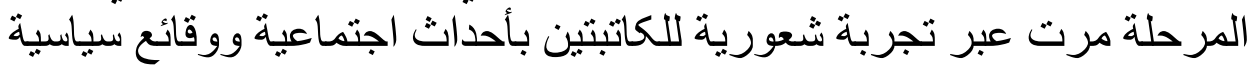

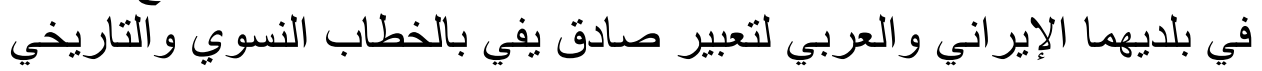

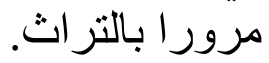

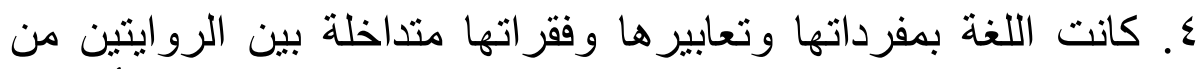

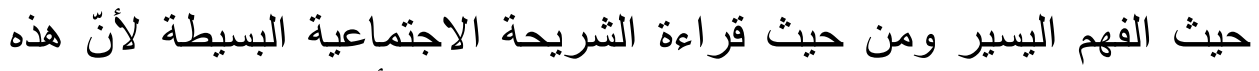

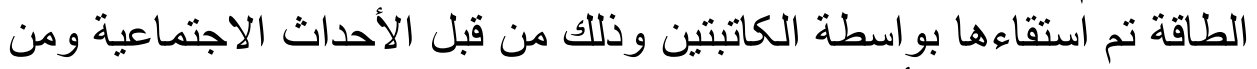

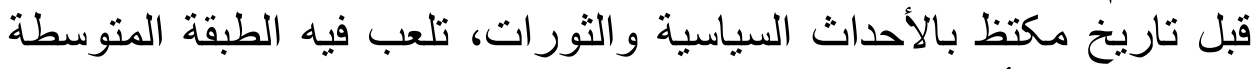

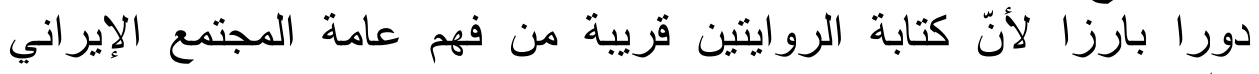
والعربي. 


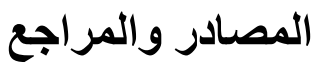

• •ِاينده، حسين، كثودن رمان، جاب دوم، تهران: انتشارات مرواريد،

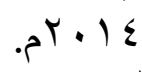

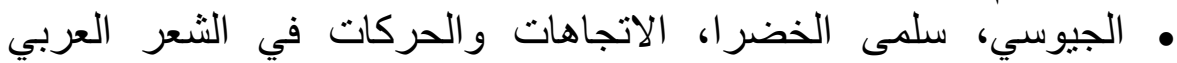

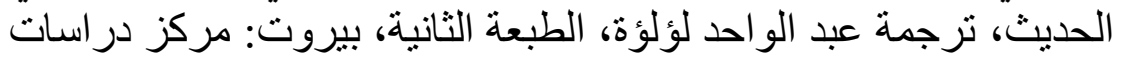

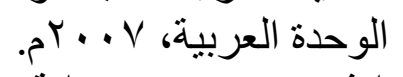

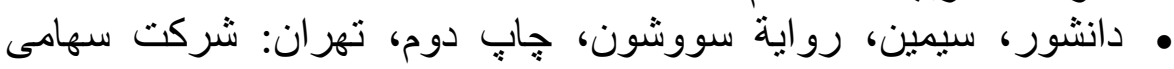

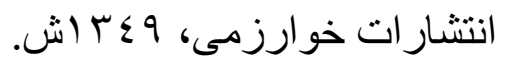
• طبانة، بدوي، التيارات المعاصرة فئرة في النقد الأدبي، الطبعة الثالثة،

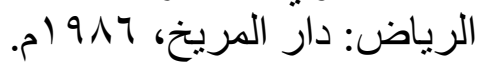

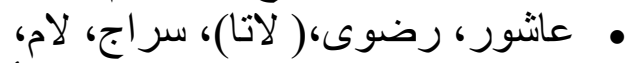
• عبد الباري، ماهر شعبان، التذوق الأدبي، الطبعة الأولى، عمان: الأردن،

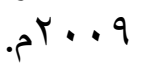
• عتيق، عبد العزيز، في النقا الأدبي، الطبعة الثانية، بيروت: دار النهضة

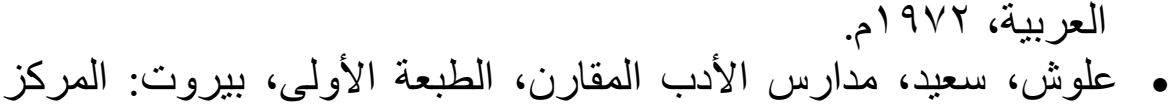

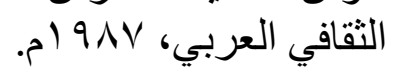

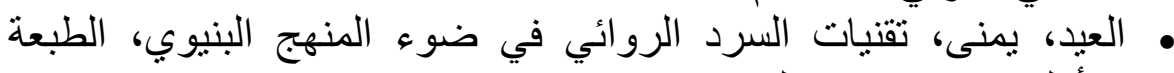

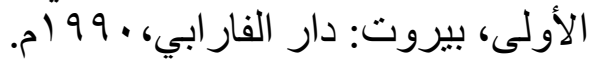

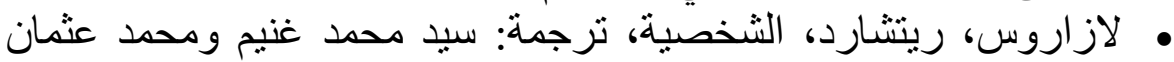

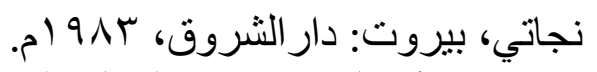

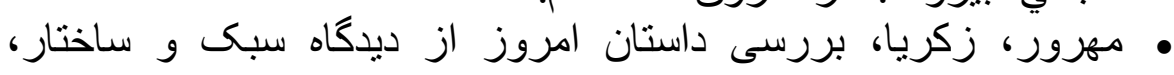

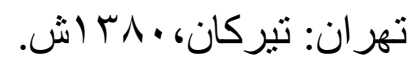
• ميرصادقي، جمال، داستان نويسان معاصر ايران، تهران: نشر اشاره،

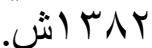

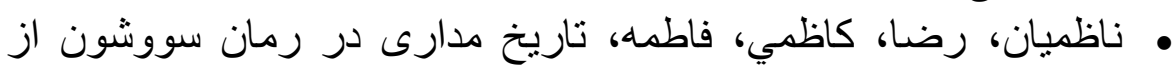

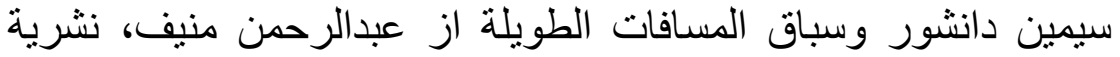

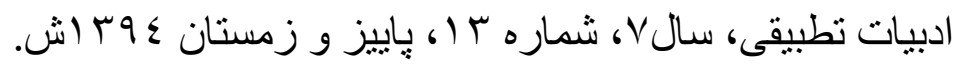

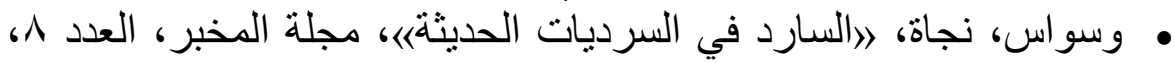




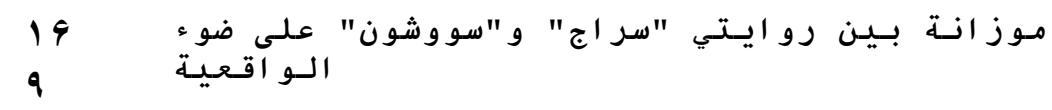

\section{References}

- Payende Hossein (2014). Opening the Novel. Second Edition, Tehran: Morvarid Publishing.

- Jafar Ali Jafar (2016). "Manifestation of feminist theory in novel Sauvushun by Iranian Novelist Simin Daneshvar, Rays of Criticism in Arabic \& Persian, V6, N22, pp. 140-170.

- Al-Jayyousi, Salma Al-Khadra (2007). Trends and Movements in Modern Arabic Poetry. Abd al-Wahid Lu'loua (Trans), second edition, Beirut: Center for Arab Unity Studies.

- Daneshvar Simin (1970). Suvushun, Second Edition, Tehran: Kharazmi Publishing Company.

- Darraj Faisal (2002). The Theory of the Narration and the Arabic Novel, 2nd Edition, Beirut: The Arab Cultural Center.

- Roshanfeker, Kobra and others (2017). "Heteroglossia in the feminist narrative, Zakerat Aljasad as a model", Journal of Adab al-Kufa.V1, N33. p:285-320.

- Tabbaneh Badawi (1986). Contemporary Currents in Literary Criticism, Third Edition, Riyadh: Dar Al-Marikh.

- Ashour Radwa (1986). Siraaj. www.kotobarabia.com

- Abd ElBari, Maher Shaban (2009), Literary Taste, First Edition, Amman: Jordan.

- Abdollahi Mahnaz (2007), "Simin Daneshvar Yearbook", Bokhara Cultural, Political, Socio-Literary Monthly, N75, pp. 34-40.

- Atiq Abdel Aziz (1972). In Literary Criticism, Second Edition, Beirut: Dar Al-Nahda Al-Arabiya.

- Alloush Said (1987). Schools of Comparative Literature, First Edition, Beirut: The Arab Cultural Center.

- Al-Eid, Youmna (1990). Narrative Techniques in Light of the Structural Curriclum, First Edition, Beirut: Dar Al-Farabi.

- Ghobadi Hossein Ali (2004). "An Analysis of Sovashon themes from the viewpoint of literary schools and social discourses", Quarterly Pizhuhish-I Zaban Va Adabiyyat_I Farsi, N. 3, pp. 41-54.

- Ghobadi Hossein Ali and the others (2009). "An Analysis of the main discourse in Sovashoon of Simin Daneshvar", Quarterly Literary Criticism, Vol. 6, No. 2, pp. 149-183.

- Richard Lazarus (1983). Personality, Seyyed Mohammad Ghanim Mohammad, Osman Nejati(Trans), Beirut: Dar alShorouq.

- Mirsadeghi Jamal (2003). Contemporary Iranian Fiction Writers, Tehran: Eshareh Publishing. 
- Mir Abedini Hassan (2004). One Hundred Years of Story Writing, Tehran: Cheshmeh.

- Nazemian, Reza, Fatima Kazemi (2015). "The history of the orbiting Savushun as Simin Daneshor and the Sebagh al-Masafte al-Tavila from Abdurrahman Munif', of Comparative literature, N 13, Vol. 7, pp. 245268.

- Waswas Najat (2012). The Narrator in Modern Narratives, Al-Mukhber Journal, vol. 8, 97-115. 


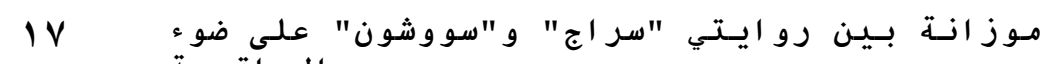 1 السو اقعيـة}

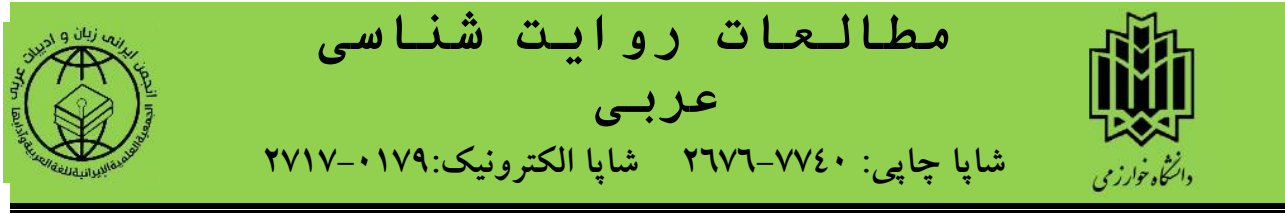

بررسى تطبيقى كفتمان روايت زنانه در ادبيات داستانى مصر وايران؛ مقايسه موردى

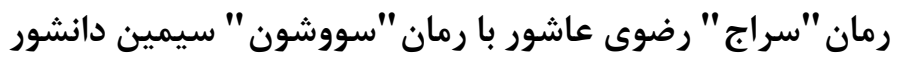

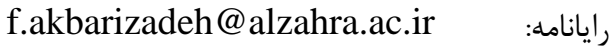
فاطمه اكبرى زاده

استاديار كروه زبان و ادبيات عربى دانشكاه الزهرا، تهران. (نويسنده مسئول) negravi321@gmail.com رايانامه:

معصومه نغراوى

دانش آموخته مقطع كارشناسى ارشد زبان و ادبيات عربى، دانشكاه الزهرا، تهران.

زن نقشيده قابل ملاحظهاى در وقايع اجتماعى وسياسى جامعه كنونى ايران ومصر داشته است؛ تا آنجاكه

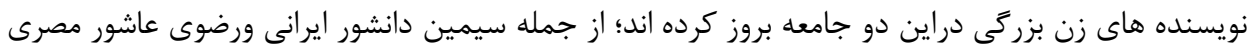

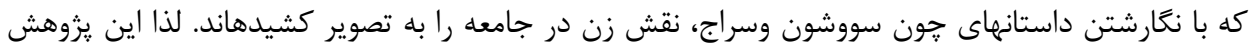

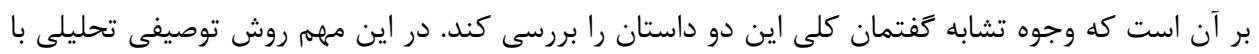

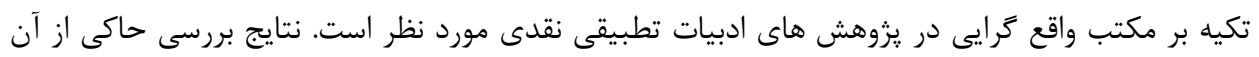

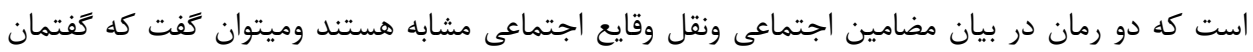

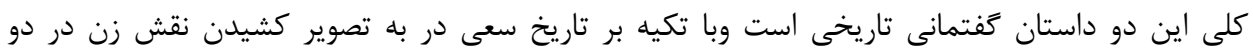

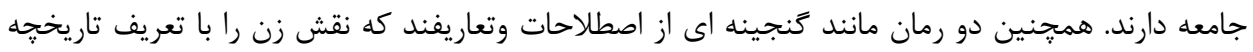

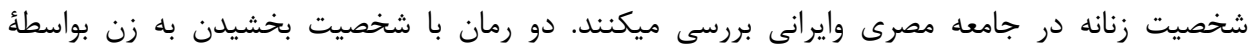

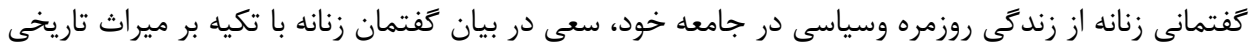

كليدوازه ها: ادبيات تطبيقى، روايت بزوهى، زن، رضوى عاشور، سيمين دانشور.

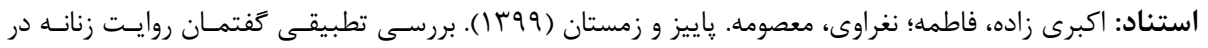

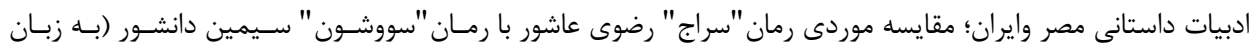

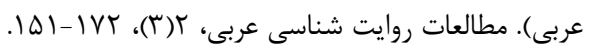

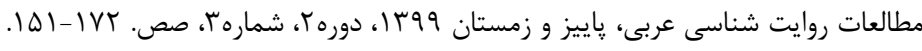

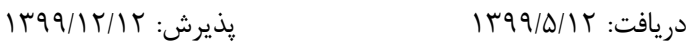

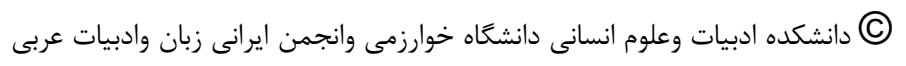

